$>$ Geochemical and hydrological model for bauxite residue sand. >Combined hydrogeochemical simulation of bauxite residue sand under field conditions, in 2D, heterogeneous domomain.

$>$ Evaluation of management practise for the amelioration of bauxite residue sand as substrate for plant growth. 
This manuscript illustrates an innovative application of detailed hydrogeochemical modelling to the field of bauxite residue management. A recently developed simulation tool that combines geochemical reaction calculations in PHREEQC with variably saturated flow and transport processes in COMSOL was employed to investigate the evolution of water availability and water quality in fertigated and amended bauxite residue sand as response to rainfall leaching. The level of detail in flow and reactions calculations is novel to studies of residue management and rehabilitation. Due to the general applicability, the employed simulation and parameterization techniques are of interest to a broad audience in the field of mining waste management. 


\section{Predictive Hydrogeochemical Modelling of Bauxite Residue Sand in Field Conditions}

Laurin Wissmeier ${ }^{*}$,a), David A. Barry ${ }^{\text {a) }}$ and Ian R. Phillips ${ }^{\text {b) }}$

a) Ecole Polytechnique Fédérale de Lausanne (EPFL)

Faculté de l'Environnement Naturel, Architectural et Construit (ENAC)

Laboratoire de Technologie Ecologique

Station 2, 1015 Lausanne, Switzerland

b) Mining Environmental Group

Alcoa of Australia Ltd.

PO Box 172 Pinjarra WA 6208, Australia

Revised and resubmitted to Journal of Hazardous Materials

19 April 2011

* Author to whom all correspondence should be addressed. Telephone: +49 761211 138-0, facsimile: +49 761211 138-29. E-mail addresses: laurin.wissmeier@epfl.ch (L. Wissmeier), andrew.barry@epfl.ch (D.A. Barry),

ian.phillips@alcoa.com.au (I.R. Phillips) 


\section{$1 \quad$ Abstract}

2 The suitability of residue sand (the coarse fraction remaining from Bayer's process of bauxite

3 refining) for constructing the surface cover of closed bauxite residue storage areas was investigated. Specifically, its properties as a medium for plant growth are of interest to ensure residue sand can support a sustainable ecosystem following site closure. The geochemical evolution of the residue sand under field conditions, its plant nutrient status and soil moisture retention were studied by integrated modelling of geochemical and hydrological processes.

8 For the parameterization of mineral reactions, amounts and reaction kinetics of the mineral 9 phases natron, calcite, tricalcium aluminate, sodalite, muscovite and analcime were derived from measured acid neutralization curves. The effective exchange capacity for ion adsorption

11 was measured using three independent exchange methods. The geochemical model, which

12 accounts for mineral reactions, cation exchange and activity corrected solution speciation,

13 was formulated in the geochemical modelling framework PHREEQC, and partially validated

14 in a saturated flow column experiment. For the integration of variably saturated flow with multi-component solute transport in heterogeneous 2D domains, a coupling of PHREEQC with the multi-purpose finite-element solver COMSOL was established. The integrated

17 hydrogeochemical model was applied to predict water availability and quality in a vertical

18 flow lysimeter and a cover design for a storage facility using measured time series of rainfall

19 and evaporation from southwest Western Australia. In both scenarios the sand was fertigated and gypsum-amended. Results show poor long-term retention of fertilizer ions and buffering

21 of the $\mathrm{pH}$ around 10 for more than 5 years of leaching. It was concluded that fertigation, gypsum amendment and rainfall leaching alone were insufficient to render the geochemical conditions of residue sand suitable for optimal plant growth within the given timeframe. The surface cover simulation demonstrates that the soil moisture status in the residue sand can be 
25 ameliorated by an appropriate design of the cover layer with respect to thickness, slope and 26 distance between lateral drains.

\section{Keywords}

28 bauxite refining residue, geochemical modelling, PHREEQC, IPhreeqc, COMSOL, PEST,

29 mineral reactions, cation exchange, vadose zone, variable saturation, revegetation, waste

30 management 


\section{Introduction}

32 The worldwide production of alumina (83.3 Mt in 2008 [1]) is associated with the creation of

33 about $120 \mathrm{Mt}$ of problematic bauxite refining residues each year [2]. In Western Australia,

34 where about a third of the alumina on the global market is produced [3], the residue is disposed of in large impoundments close to the refineries, where it is left to drain and air-dry (dry-stacking) [4, 5]. In anticipation of future storage capacity limits, the bauxite refining industry seeks safe and economically feasible strategies of sustainable storage site closure. Important objectives for successful closure are [6-11]

- reduction of infiltration into the underlying residue;

- dust control;

- erosion control;

- minimization of the need for future reworking; and,

- limitation of the visual obtrusiveness.

44 These objectives could be achieved by a self-sustaining vegetation cover on top of residue storage areas. Since the reuse of residue sand (the coarse fraction of the residue; characteristic grain size $>10^{-4} \mathrm{~m}$ ) as a medium for plant growth would greatly reduce the costs of

47 revegetation, research into its suitability as a substrate has been recently intensified.

48 However, plant productivity on residue sand is impeded by the geochemical conditions that reactions of highly unstable minerals impose on the soil solution [12]. Characteristic properties of the residue sand are [7, 11, 13-15]:

- $\quad$ high pH (10-12.5);

- high total alkalinity (ca. $20 \mathrm{meq}^{-1}$ );

- high electrical conductivity (ca. $1500 \mu \mathrm{S} \mathrm{cm}^{-1}$ ); and,

- high exchangeable sodium percentage (close to $100 \%$ ). 
Besides the general geochemical conditions, the plant nutrient status in the residue sand plays a critical role for the long-term revegetation success $[8,12,15]$. Chen et al. $[16,17]$ therefore investigated the retention of major nutrients in residue sand after additions of a standard ammonium-phosphate fertilizer. In [17], they specifically focused on the loss of ammonia $\left(\mathrm{NH}_{3}\right)$ due to volatilization. Fractionation and availability of micronutrients such as $\mathrm{B}, \mathrm{Cu}$, $\mathrm{Fe}, \mathrm{Mn}$ and $\mathrm{Zn}$ in residue sand was examined by Thiyagarajan et al. [10]. Motivated by the observed Mn deficiency of plants on residue sand, Gherardi and Rengel [13] investigated the detailed fractionation of this essential nutrient. Phillips and Chen [14] studied ion adsorption onto variable charge adsorption sites as the main fractionating process for micronutrients.

To date the interference on adsorption sites of fertilizer retention and mineral dissolution reactions as result of ion competition remains unclear. More importantly, the influence of soil moisture dynamics and solute transport on the geochemical factors that determine sand fertility in field conditions is largely unknown. Under natural leaching conditions, imposed by rainfall and evaporation, geochemical processes of ion adsorption and mineral dissolution are controlled by variably saturated soil moisture movement and influenced by changes in local ion concentrations due to solute transport [18-21]. Therefore, flow and transport are crucial components in the assessment of the long-term efficiency of management strategies, such as fertilizer addition or gypsum amendment [22-24]. Besides its importance for ion transport and solution reactivity, water availability plays a key role in residue sand fertility.

Integrated hydrogeochemical modelling is a powerful tool to investigate simultaneous geochemical reactions, such as mineral reactions and ion adsorption, considering their dependency on soil moisture dynamics and solute transport [25-28]. Here, we present the first interdisciplinary modelling of bauxite refining residue sand by combining geochemical reactions with rainfall- and evaporation-induced variably saturated flow in $2 \mathrm{D}$ heterogeneous 
and hydrological processes in residue sand, and (2) to predict the long-term effect of

81 fertilization and gypsum amendment on residue sand fertility in field conditions through

82 integrated hydrogeochemical modelling.

83 The paper is structured as follows: A geochemical model for residue sand is established in

84 Section 2. Mineral reactions are derived from measured acid neutralization curves in

85 combination with speciation modelling and linked parameter optimization. Ion adsorption is

86 considered by a cation exchange process using independent measurements to determine the

87 effective exchange capacity. The model is formulated in the geochemical modelling

88 framework PHREEQC [29] and is partially validated against results from saturated-flow

89 column experiments. Section 3 presents the hydraulic properties of residue sand with

90 relevance to hydrological modelling. The software for coupled simulations of geochemistry

91 and unsaturated hydrological processes is described briefly in Section 4. Details of novel

92 model features and the implementation of atmospheric boundary conditions are provided in

93 Appendices A-C. Section 5 describes the meteorological conditions at ALCOA's Pinjarra

94 Alumina Refinery in south-west Western Australia where the model is applied. Results from

95 predictive simulations of a constructed lysimeter and a surface cover design for residue

96 storage areas are presented in Sections 6 and 7. The main model uncertainties are discussed in

97 Section 0 together with implications for residue management. Conclusions with respect to the

98 fertilizer addition and gypsum amendment as well as the overall suitability of residue sand as

99 a plant growth substrate are drawn in Section 9. 


\section{Geochemical Model}

101

\subsection{Solid Phase Properties}

102 The geochemistry of fresh, untreated residue sand is dominated by dissolution of readily

103 soluble salts and minerals [e.g., 30]. In order to simulate the geochemical conditions as a

104 response to fertigation, gypsum amendment and rainfall leaching, detailed knowledge of the

105 stoichiometry, quantity and reactivity of the soluble minerals is required. Taylor and Pearson

106 [31] found 58\% quartz, 22\% hematite, $7 \%$ gibbsite, $5 \%$ goethite, $1 \%$ anatase, $1 \%$ muscovite

107 and $0.3 \%$ boehmite as the major mineral fractions in residue sand. Because of their low

108 solubility and/or slow reactions kinetics, these major mineral fractions contribute little to the

109 overall geochemical conditions in the soil solution. Instead, highly reactive salts such as

110 natron $\left(\mathrm{Na}_{2} \mathrm{CO}_{3}: 10 \mathrm{H}_{2} \mathrm{O}\right)$, calcite $\left(\mathrm{CaCO}_{3}\right)$, tricalcium aluminate $\left(\mathrm{TCA} ; \mathrm{Ca}_{3} \mathrm{Al}_{2} \mathrm{O}_{6}\right)$ [32-34]

111 and the desilication product (DSP; e.g., sodalite $\left.\mathrm{Na}_{8}\left(\mathrm{AlSiO}_{4}\right)_{6} \mathrm{Cl}_{2}\right)[15,35-40]$ are responsible

112 for the high $\mathrm{pH}$ and large acid neutralization capacity of the bauxite residue [30, 41].

113 Although identified qualitatively by XRD [30], the proportions of these minerals in residue

114 sand is currently unknown.

115 For the parameterization of the geochemical model, the reactive mineral proportions were

116 found by matching measured acid neutralization curves with simulations performed in

117 PHREEQC. In this approach, the solution $\mathrm{pH}$ was regarded as a master variable and an

118 integrated measure for the overall geochemical conditions [42]. Similar to the procedure used

119 by Snars and Gilkes [30], buffering plateaus are associated with the dissolution of distinct

120 mineral phases and the persistence of buffering regions is related to the amount of the

121 minerals in the mineral assembly.

122 Acid neutralization was measured over the $\mathrm{pH}$ range of $2-12.30 \mathrm{~g}$ of residue sand $(\varnothing<2$

$123 \mathrm{~mm}$, oven-dried for $>2 \mathrm{~d}$ at $50^{\circ} \mathrm{C}$ ) were placed into a series of 20 polystyrol screw-lid 
124 beakers (190 ml, Semadeni). A $0.5 \mathrm{M} \mathrm{HCl}$ solution was added to the beakers in quantities 125 ranging from 0 to $14.25 \mathrm{ml}$ in steps of $0.75 \mathrm{ml}$. The beakers were made up to volume using

126 Milli-Q deionised water to achieve a liquid to solid ratio of 5:1 by weight. Samples were

127 thoroughly mixed (20 rpm) using an end-over-end shaker. Excessive gas phase equilibration

128 was avoided by reducing the empty volume in each beaker to ca. $20 \mathrm{ml}$. The $\mathrm{pH}$ of each

129 suspension was recorded 2, 4, 24, 48, 72 and $96 \mathrm{~h}$ after acid addition using a robotic

130 titrosampler (Metrohm 855) with a platinum electrode (Metrohm 6.0257.000 Aquatrode

131 Plus).

132 Fig. 1: Measured (a) and simulated acid neutralization curves at thermodynamic equilibrium (b) and including the 133 kinetic dissolution of TCA and sodalite (c).

134 Acid neutralization curves show distinct buffering plateaus at $\mathrm{pH} 7$ and $\mathrm{pH} 4$ and a less

135 pronounced buffering region around $\mathrm{pH}$ 9-10 (Fig. 1a). Over time, acid consumption

136 increased due to kinetic mineral dissolution, giving the impression of a moving $\mathrm{pH}$ front.

137 After $72 \mathrm{~h}$, the $\mathrm{pH}$ stabilised, suggesting that readily soluble alkalinity was consumed and that

138 fast kinetic reactions attained quasi-equilibrium. The extent of further buffering due to slowly

139 reacting minerals remains uncertain. However, over the time scale examined, the acid

140 neutralisation curves provide reliable information on the effects of acid on the geochemical

141 behaviour of residue sand.

142 In the first step of the model development, the acid neutralization at $2 \mathrm{~h}$ was reproduced by

143 simulating the solution in equilibrium with the fast reacting minerals natron, calcite,

144 muscovite and analcime. The latter two minerals provide buffering around $\mathrm{pH} 4$ and are

145 therefore of minor importance under conditions typically observed for residue sand deposited

146 in the field $(\mathrm{pH}>7)$. The quantity of natron and calcite were optimized to match the

147 measured acid neutralization curve through coupling PHREEQC with the model-independent

148 parameter estimation software PEST (version 12) [43]. The second step in model 
149 development introduced the minerals TCA and sodalite, whose quantities were optimised in

150 PHREEQC to reproduce the acid neutralisation curve observed after $96 \mathrm{~h}$ of reaction time.

151 The mineral sodalite was included as a surrogate to represent the variety of components in the

152 desilication product [44]. Similarly, TCA represents the mineral group of calcium aluminates.

153 Since the buffering capacity around $\mathrm{pH} 4$ was not exhausted during the experiment, the

154 amount of muscovite was estimated from the mineralogical data of Taylor and Pearson [31]

155 given above. The amount of sodium $(\mathrm{Na})$ in fresh residue sand that is not accounted for by

156 natron and sodalite was attributed to analcime. Reactive $\mathrm{Na}$ as measured by leach testing over

157 a range of $\mathrm{pH}$ from 0.8 to 11.8 (data not shown) amounts to $5.415 \times 10^{-3} \mathrm{~g} \mathrm{~g}^{-1}$. Measured and

158 simulated acid neutralization curves at 2 and $96 \mathrm{~h}$ are presented in Fig. $1 \mathrm{~b}$. In a third step of

159 model development, acid neutralization between 2 and $96 \mathrm{~h}$ was attributed to kinetic

160 dissolution of TCA and sodalite. In agreement with transition state theory [e.g., 45], the rate

161 expression

$s_{i} \frac{d m_{i}}{d t}=k(1-\Omega) A\left(\frac{M}{M_{0}}\right)^{\frac{2}{3}}$

162 given by the PHREEQC manual [29] was employed. In Eq. (1), $s_{i}$ is the stoichiometric factor

163 of component $i$ in the mineral phase, $m_{i}$ is the quantity of component $i$ in the liquid phase

164 (mol), $k$ is the rate constant $\left(\mathrm{mol} \mathrm{m}^{-2} \mathrm{~s}^{-1}\right), \Omega$ is the saturation ratio and $A$ is the mineral surface

165 area $\left(\mathrm{m}^{2}\right)$. The factor $\left(\frac{M}{M_{0}}\right)^{\frac{2}{3}}$ accounts for the change in mineral surface with dissolution

166 progress for spherical mineral grains, where $M$ is the current amount of mineral (mol) and $M_{0}$

167 is the initial amount of mineral (mol). The saturation ratio $\Omega$ is defined by

$$
\Omega=\frac{\prod a_{i}^{s_{i}}}{K}
$$


where $a_{i}$ is the activity of component $i$ and $K$ is the equilibrium constant of the

169 dissolution/precipitation reaction. The reactive surface area $A$ of the mineral phases was set

170 equal to the total surface area of residue sand. The total surface area $\left(2.708 \times 10^{-2} \mathrm{~m}^{2} \mathrm{~g}^{-1}\right)$ was

171 calculated from laser diffraction particle analysis (LSTM 13 320, Beckman Coulter) assuming

172 spherical particles (see Appendix D). The rate constant $k$ and the initial amount $M_{0}$ were

173 estimated by matching all measured acid neutralization curves at all time periods between 2

174 and $96 \mathrm{~h}$ of reaction by the coupling of PHREEQC and PEST (Fig. 1c). The derived mineral

175 properties for subsequent modelling are summarized in Table 1.

Table 1: Mineral properties of residue sand as derived from acid neutralization.

Mineral name

Reaction formula
Equilibriu Rate constant Relative $\mathrm{m}$ constant $\left(\mathrm{mol} \mathrm{m}^{-2} \mathrm{~s}^{-1}\right)$ amount ( $\mathrm{mol}$ $\mathrm{kg}_{\text {solid }}{ }^{-1}$ )

Calcite

$\mathrm{CaCO}_{3}=\mathrm{CO}_{3}^{-2}+\mathrm{Ca}^{+2}$

Natron

$\mathrm{Na}_{2} \mathrm{CO}_{3}: 10 \mathrm{H}_{2} \mathrm{O}=2 \mathrm{Na}^{+}+\mathrm{CO}_{3}{ }^{-2}+10 \mathrm{H}_{2} \mathrm{O}$

Muscovite

$\mathrm{KAl}_{3} \mathrm{Si}_{3} \mathrm{O}_{10}(\mathrm{OH})_{2}+10 \mathrm{H}^{+}=\mathrm{K}^{+}+3 \mathrm{Al}^{+3}+$

$3 \mathrm{H}_{4} \mathrm{SiO}_{4}$

Analcime

$\mathrm{NaAlSi}_{2} \mathrm{O}_{6}: \mathrm{H}_{2} \mathrm{O}+\mathrm{H}_{2} \mathrm{O}+4 \mathrm{H}^{+}=\mathrm{Na}^{+}+\mathrm{Al}^{+3}+$

$2 \mathrm{H}_{4} \mathrm{SiO}_{4}$

Sodalite

$\mathrm{Na}_{8}\left(\mathrm{AlSiO}_{4}\right)_{6} \mathrm{Cl}_{2}+24 \mathrm{H}_{2} \mathrm{O}=8 \mathrm{Na}^{+}+$

$6 \mathrm{Al}(\mathrm{OH})_{4}{ }^{-}+$

$6 \mathrm{H}_{4} \mathrm{SiO}_{4}+2 \mathrm{Cl}^{-}$

TCA

$\mathrm{Ca}_{3} \mathrm{Al}_{2} \mathrm{O}_{6}+12 \mathrm{H}^{+}=3 \mathrm{Ca}^{+2}+2 \mathrm{Al}^{+3}+6 \mathrm{H}_{2} \mathrm{O}$

$$
10^{6.719 \mathrm{a}} \quad-\quad 3.054 \times 10^{-2}
$$

$10^{-8.48 \mathrm{a}} \quad-\quad 2.531 \times 10^{-2}$

$10^{14 \mathrm{~b}} \quad-\quad 2.511 \times 10^{-2}$

${ }^{a}$ minteq.dat (distributed with PHREEQC), ${ }^{b}$ sit.dat (distributed with PHREEQC), ${ }^{c}$ calculated from

178 thermodynamic data in Komada et al. [46], ${ }^{\mathrm{d}}$ Khaitan et al. [34]

179 The results in Fig. 1b show excellent agreement between the simulated and measured acid

180 neutralization curves after $2 \mathrm{~h}$ using the fast reacting minerals natron and calcite to represent 
the buffering regions at $\mathrm{pH} 7$ and around $\mathrm{pH} 10$. The correlation coefficient according to

182 Cooley and Naff [47] amounts to 0.995 . The measured decline in $\mathrm{pH}$ with the addition of 2

183

184

185

186

187

188

189

190

191

192

193

194

195

196

197

198

199

200

201

202

203 mmol $\mathrm{HCl}$ as well as the exhaustion of the buffering capacity after addition of $7 \mathrm{mmol} \mathrm{HCl}$ is well reproduced. However, the $\mathrm{pH}$ is overestimated by about one $\mathrm{pH}$ unit in the strongly alkaline region $(\mathrm{pH}>9)$, whereas it is slightly underestimated for the addition of 2-7 mmol acid. This is reflected also by the lower correlation coefficient of 0.973 . The simulation of kinetic $\mathrm{pH}$ buffering in Fig. 1c, with an overall correlation coefficient of 0.982 , shows that simple rate expressions are sufficient to produce reasonable agreement of this time-dependent process. Since the field $\mathrm{pH}$ remains always in the alkaline range, the mismatch between measured and simulated $\mathrm{pH}$ below 7 is of lower importance.

\subsection{Adsorption Properties}

The adsorption of fertilizers as result of cation exchange is critical to the understanding of nutrient retention, which is crucial for plant growth. The effective cation exchange capacity (CEC) of residue was measured using three independent methods: (i) the method of Ca-Mg exchange for soils containing salts, carbonates and zeolites [48], (ii) the unbuffered salt extraction method at field $\mathrm{pH}$ [modified after 49, in 50], and (iii) the cobalt hexamine compulsive exchange method [51]. Measurements were taken from three replicates using each method.

Prior to testing, the residue sand was washed to avoid errors due to the dissolution of readily soluble salts. $40 \mathrm{~g}$ of oven-dried sand $\left(50^{\circ} \mathrm{C},>2 \mathrm{~d}, \varnothing<0.5 \mathrm{~mm}\right)$ were weighed into a $250 \mathrm{ml}$ Nalgene bottle, after which $200 \mathrm{ml}$ of water (Milli-Q) was added to achieve a liquid to solid ratio of 5:1. The bottles were shaken end-over-end for $1 \mathrm{~h}$ and centrifuged at $2 \times 10^{3} \mathrm{rpm}$ for $30 \mathrm{~min}$. The clear supernatant was manually decanted and care was taken not to lose any of the fine material that deposited as a red layer on top of the coarse sand. Subsequently, the 
bottles were made up to volume. The washing procedure was repeated 10 times, during which

206 the electrical conductivity decreased from $1513 \mu \mathrm{S} \mathrm{cm}^{-1}$ to $53 \mu \mathrm{S} \mathrm{cm}^{-1}$ indicating the removal

207 of the most soluble mineral fractions [52].

Table 2: Cation exchange capacity on washed residue sand.

\begin{tabular}{ll}
\hline Method & $\mathrm{CEC}\left(\mathrm{cmol} \mathrm{kg}_{\text {solid }}{ }^{-1}\right)$ \\
\hline (i): $\mathrm{Ca}-\mathrm{Mg}$ & 0.66 \\
(ii): $\mathrm{NH}_{4}-\mathrm{K}$ & 1.21 \\
(iii): $\mathrm{Co}\left(\mathrm{NH}_{3}\right)_{6} \mathrm{Cl}_{3}$ & 0.72 \\
\hline
\end{tabular}

209 Each of the three methods yielded CEC values of the same order of magnitude (Table 2).

210 However, the value from the $\mathrm{NH}_{4}-\mathrm{K}$ exchange method was about twice as high as results

211 from the other two methods. The Ca-Mg exchange method and the cobalt hexamine method

212 lower the native $\mathrm{pH}$ of the residue sand. This may decrease the number of $\mathrm{pH}$-dependent

213 surface sites, which could explain the lower measured exchange capacity. In the following

214 model applications the arithmetic mean of all three methods (CEC: $0.86 \mathrm{cmol} \mathrm{kg}_{\text {solid }}{ }^{-1}$ ) was

215 used as the effective exchange capacity of residue sand. For the definition of ion association

216 reactions, PHREEQC's default database phreeqc.dat was employed.

\subsection{Column Study for Model Validation}

218 Before modelling fertiliser transport under field conditions, the model representation of

219 geochemical processes under controlled laboratory conditions was evaluated. A column

220 leaching experiment in saturated upward flow conditions was performed to provide partial

221 validation of the geochemical model by comparison of simulated and measured $\mathrm{pH}$, electrical

222 conductivity and element concentrations in the outflow. The experimental setup is displayed

223 in Fig. 2.

Fig. 2: Upward flow column experiment. 
225 In order to achieve homogenous packing, the untreated, oven-dried residue sand $\left(50^{\circ} \mathrm{C},>2 \mathrm{~d}\right.$, $\varnothing<2 \mathrm{~mm}$ ) was poured into a glass column in portions of $5 \pm 2 \mathrm{~g}$ while a head of $2-5 \mathrm{~cm}$ of

227 Milli-Q water was maintained in the column [wet packing, 53]. This packing achieved a final 228 bulk density of about $1.56 \mathrm{~g} \mathrm{~cm}^{-3}$. No particle separation was observed in the sand column 229 after packing. Deionised water was supplied at the base (inflow) of the vertical column at a 230 constant flux $\left(15.03 \mathrm{~cm}^{3} \mathrm{~min}^{-1}\right)$ using a peristaltic pump (Ismatec MCP). The discharge was 231 collected above the outflow plug in $75.15 \mathrm{~cm}^{3}$ aliquots, and retained for analysis. Column 232 properties are shown in Table 3.

233 Table 3: Column properties.

\begin{tabular}{ll}
\hline Property & Value \\
\hline Column diameter & $40 \mathrm{~mm}$ \\
Column length & $600 \mathrm{~mm}$ \\
Flux & $15.03 \mathrm{~cm}^{3} \mathrm{~min}^{-1}$ \\
Porosity & 0.43 \\
Fill volume & $600 \mathrm{~cm}^{3}$ \\
\hline
\end{tabular}

234 The leaching experiment was performed in three replicates (Series I, II and III). Automated 235 measurements of $\mathrm{pH}$ and electrical conductivity in the outflow aliquots were taken using a 236 robotic titrosampler (Metrohm 855 Robotic Titrosampler) in combination with appropriate 237 electrodes (Metrohm 6.0257.000 Aquatrode Plus, Metrohm 712 Conductometer with 238 Metrohm 6.0912.110). For alkalinity measurements, samples were immediately titrated to $\mathrm{pH}$

2394.3 with $0.01 \mathrm{M} \mathrm{HCl}$ using an automated titrator (Metrohm 800 Dosino). The $\mathrm{CO}_{2}$ gas

240 saturation was calculated from $\mathrm{pH}$ and alkalinity measurements using PHREEQC by

241 attribution of alkalinity to carbonate species, protons and hydroxyl ions. Major element 242 concentrations were measured in the outflow of Series III using an ICP-OES instrument 
243 (Perkin Elmer Optima 3300 DV). Samples were filtered (Whatman Spartan $300.45 \mu \mathrm{m}$ ),

244 acidified to $\mathrm{pH}<2$ using $\mathrm{HCl}$ and stored at $4{ }^{\circ} \mathrm{C}$ prior to analysis.

245 The column experiment was simulated using PHREEQC's 1D-transport capabilities and the 246 geochemical properties that were derived in Sections 2.1 and 2.2. The initial pore water and 247 the inflowing solution were assumed to be in equilibrium with atmospheric $\mathrm{CO}_{2}$ and $\mathrm{O}_{2}$. Ion 248 diffusion and physical dispersivity were estimated as $3 \times 10^{-10} \mathrm{~m}^{2} \mathrm{~s}^{-1}$ and $10^{-1} \mathrm{~m}$, respectively.

249 Flushing the column with 100 pore volumes corresponds to approximately $35 \mathrm{y}$ of rainfall 250 leaching in the climatic conditions of Western Australia with an estimated annual effective 251 recharge of $600 \mathrm{~mm}$ (see Section 5). Measured and simulated $\mathrm{pH}$, alkalinity, electrical 252 conductivity (EC) and $\mathrm{CO}_{2}$ saturation in the discharge are presented in

253 Fig. 3.

Fig. 3: Results of column experiment for $\mathrm{pH}(\mathrm{a})$, alkalinity (b), electrical conductivity (c) and calculated $\mathrm{CO}_{2}$ saturation (d).

256 The $\mathrm{pH}$ buffering simulated with the suggested mineral assembly agrees well with

257 observations (

258 Fig. 3a). The overestimation of $\mathrm{pH}$ during the first few pore volumes can be attributed to the 259 assumed thermodynamic equilibrium with natron. The simulation of electrical conductivity

260 according to solution species mobility matches well the observations (

261 Fig. 3c). Alkalinity (

262 Fig. 3b), which mainly results from carbonate species, was overestimated by the model,

263 possibly due to equilibration with calcite. Despite this, reasonable agreement for $\mathrm{CO}_{2}$ -

264 saturation in the column simulation was achieved (

265 Fig. 3d). 
266 Results of the element analysis together with modelled total element concentrations in the

267 column outflow are displayed in Fig. 4.

268 Fig. 4: Element concentrations $\left(\mathrm{mol} \mathrm{l}^{-1}\right)$ in the column outflow for (a) $\mathrm{Na}$, (b) $\mathrm{K}$, (c) $\mathrm{Al}$ and (d) $\mathrm{Ca}$.

269 The simulation of $\mathrm{Na}$ concentrations in Fig. 4a agrees very well with observations.

270 Concentrations of potassium (K) (Fig. 4b) are largely underestimated due to the low

271 solubility of muscovite, which is the only source of K in the chosen mineral model.

272 Aluminium (Al) concentrations in Fig. 4c are overestimated by an order of magnitude

273 compared to measurements. This suggests too high solubility constants for DSP and TCA

274 obtained from the literature or reprecipitation of $\mathrm{Al}$ in the form of aluminium oxides such as

275 gibbsite and boehmite or aluminium silicates. The mismatch of Ca concentrations in Fig. 4d

276 together with the overestimated alkalinity from

277 Fig. 3b suggests that calcite may not be present as a pure phase, although it is modelled as 278 such.

279 Overall, the comparison of measured and modelled drainage composition shows that large 280 uncertainties exist in setting key mineralogical properties of residue sand. Despite these

281 shortcomings, the geochemical model is considered suitable for estimating the geochemical

282 evolution of residue sand in field conditions because it is capable of reproducing main

283 geochemical features such as $\mathrm{pH}, \mathrm{EC}$ and $\mathrm{Na}$ concentrations.

\section{Hydraulic Model}

285 For the hydraulic characterization of residue sand in variably saturated flow conditions the

286 van Genuchten/Mualem model $[54,55]$ for water retention and unsaturated hydraulic

287 conductivity as in [56] was used. The van Genuchten function [55] is given by 
$\theta(h)=\left\{\begin{array}{cc}\theta_{r}+\frac{\theta_{s}-\theta_{r}}{\left[1+(\alpha h)^{n}\right]^{m}}, & h<0 \\ \theta_{s}, & h \geq 0\end{array}\right.$,

288 where $h$ is the pressure head $(\mathrm{cm}), \theta$ is the actual moisture content, $\theta_{r}$ is the residual moisture 289 content, $\theta_{s}$ is the saturated moisture content and $\alpha\left(\mathrm{cm}^{-1}\right), n$ and $m=1-\frac{1}{n}$ are soil-specific

290 parameters. The free parameters were determined by fitting Eq. (3) to measurements of water

291 retention that were taken in a pressure range of $0-15$ bars using the RETC code [57].

292 Unsaturated hydraulic conductivity according to the Mualem model [54] is given by

$K(\Theta)=K_{S} \Theta^{l}\left[1-\left(1-\Theta^{\frac{1}{m}}\right)^{m}\right]^{2}$

293 where $\Theta=\frac{\theta-\theta_{r}}{\theta_{s}-\theta_{r}}$ is the reduced moisture content. The parameter $l$ was taken as 0.5 . The

294 saturated hydraulic conductivity $K_{S}\left(\mathrm{~m} \mathrm{~d}^{-1}\right)$ of the residue sand was measured in situ at

295 various depths using a Guelph constant head permeameter. Its value at the soil surface was

296 measured as $12.008 \mathrm{~m} \mathrm{~d}^{-1}$. Measured values of water retention and the best fit of the van

297 Genuchten function with parameters $\alpha=0.075 \mathrm{~cm}^{-1}, n=1.822, \theta_{s}=0.454$ and $\theta_{r}=$

2980.039 are displayed together with unsaturated conductivity in Fig. 5.

Fig. 5: Water retention and unsaturated hydraulic conductivity of residue sand at the soil surface according to the 300 van Genuchten/Mualem model.

301 Conductivity measurements suggest a non-linear relation between $K_{S}$ and distance to the soil

302 surface $z(\mathrm{~m})$ of the form:

$K_{S}(z)=a \exp (b z)$

303 which was fitted to the data using a least square criterion. The parameters $a$ and $b$ were

304 determined as $12.008 \mathrm{~m} \mathrm{~d}^{-1}$ and $-0.885 \mathrm{~m}^{-1}$, respectively, with a coefficient of determination 305 of 0.92 . 
The saturated water content $\theta_{s}$ up to a depth of $3 \mathrm{~m}$ was calculated from the measured $\theta_{s}$ at

307 the surface and measured values of dry bulk density $\left(1.3 \mathrm{~g} \mathrm{~cm}^{-3}\right.$ at the surface versus $1.5 \mathrm{~g}$

$308 \mathrm{~cm}^{-3}$ at $3 \mathrm{~m}$ depth). Assuming a constant solid density, a linear relation between depth and

$309 \theta_{s}$ was established according to

$\theta_{s}(z)=c z+d$,

310 with $c=0.028 \mathrm{~m}^{-1}$ and $d=0.454$. Depth-dependent measurements of $K_{s}$ and $\theta_{s}$ together with

311 the fitted Eqs. (5) and (6) are displayed in Fig. 6.

312 Fig. 6: Depth dependence of saturated hydraulic conductivity $K_{s}$ (left) and saturated water content $\theta_{s}$ (right).

313 All other parameters in the van Genuchten/Mualem hydraulic model were assumed constant

314 throughout the profile.

315 Transverse and longitudinal dispersivity in the residue sand were estimated as $10^{-1} \mathrm{~m}$. For

316 simplicity, the influences of water saturation $[58,59]$ and scale $[60]$ were neglected. The

317 coefficient of molecular diffusion was taken as $3 \times 10^{-10} \mathrm{~m}^{2} \mathrm{~s}^{-1}$ according to the PHREEQC

318 default settings (temperature of $25^{\circ} \mathrm{C}$ ).

3194 Software for Integrated Hydrogeochemical Modelling

320 Processes of variably saturated liquid phase flow, multi-component solute transport and

321 geochemical reactions according to the geochemical and hydraulic properties described

322 earlier were combined into an integrated hydrogeochemical model of bauxite residue sand.

323 The employed software results from coupling the multipurpose finite element solver

324 COMSOL [61] with a component object model (COM) version of IPhreeqc. IPhreeqc is a

325 version of the geochemical modelling framework PHREEQC [29] that is specifically

326 designed for coupling to multi-component solute transport simulators [62]. 
328 The main modules of the coupled software and their interactions are illustrated in Fig. 7. The coupling code is executed within the MATLAB scripting environment [63], which contains

330 the split-operator procedure, manages data transfer between the modules and performs pre-

331 and post-processing tasks. From MATLAB, the computation of aqueous phase flow and

332 solute transport for a single time step is directed to the COMSOL module. After updated

333 liquid phase saturations and solute concentrations are transferred back to the MATLAB workspace, the assembly of chemical components that constitutes the liquid phase is sent to IPhreeqc for geochemical speciation using its COM interface. The main advantage over existing couplings of flow and multispecies transport codes with PHREEQC as reaction engine, such as PHTRAN [64], PHT3D [65] and PHWAT [66], results from the fact that

338 IPhreeqc saves in memory the entire geochemical system state between calls to it. Thus, only the information that is relevant to flow and transport computations (liquid phase saturation and element concentrations) needs to be extracted and transferred to COMSOL. In addition,

341 the data transfer is processed entirely in memory, which avoids inefficient writing and

342 reading of data files. A detailed presentation of the software is provided in [67]. Additional

343 features that were specifically implemented for the presented simulations of bauxite residue 344 sand are documented in the Appendices A-C.

\section{Meteorological Conditions}

346 In the absence of vegetation, rainfall and evaporation are the driving forces of soil moisture

347 movement and solute transport in the field. Thus, the geochemical evolution of residue sand,

348 the volumes of drainage, and the magnitude of fertiliser leaching, strongly depend on the

349 local meteorological conditions. Daily rainfall and pan evaporation were obtained from

350 ALCOA's meteorological records for the Pinjarra residue storage area (latitude: -32.647036, 
351 longitude: 115.930309). Missing values in the evaporation time series were reconstructed by

352 fitting the amplitude and phase of a sine function with wavelength of $365 \mathrm{~d}$ to the measured

353 data. The dominance of seasonal fluctuations of evaporation was verified by means of Fourier

354 analysis. Gaps in precipitation records were filled by linear interpolation between

355 measurements. Mean annual precipitation after the reconstruction of missing data amounts to

$3561005 \mathrm{~mm}$. This value agrees well with the $967 \mathrm{~mm} \mathrm{y}^{-1}$ measured at the town of Pinjarra

357 during the period 1877-1991 [68]. The mean annual value of reconstruction potential

358 evaporation ( $2400 \mathrm{~mm} \mathrm{y}^{-1}$ ) is considerably higher than the value of $2075 \mathrm{~mm} \mathrm{y}^{-1}$ from an

359 independent 10-y record (1980-1990) [69]. Nevertheless, the interpolation method for

360 potential evaporation was retained because the influence of evaporation on the overall water

361 balance in the highly conductive sand is limited by water availability in the surface layer. The

362 reconstructed time series of rainfall and potential evaporation at the Pinjarra residue storage

363 site are illustrated in Fig. 8.

364 Fig. 8: Time series of rainfall and potential evaporation with reconstructed missing values.

365 In its current form, the model represents bare residue sand prior to or shortly after plant

366 seeding. Therefore, the influence of plants on water availability and water quality is not

367 incorporated in the model. As shown in Wissmeier and Barry [67], however, element-specific

368 root water uptake can be included into the model by using space- and pressure-dependent

369 sink terms in solute transport equations.

\section{Simulation of a Field Lysimeter}

371 Currently, no data on fertiliser leaching in residue sand profiles under field conditions are

372 available. At ALCOA's Pinjarra site, however, a field lysimeter has recently been constructed

373 to quantify water and nutrients dynamics in rehabilitated residue sand [70]. In the following,

374 we present a simulation of the geochemical evolution of fertigated and gypsum-amended 
residue sand in this field lysimeter in response to rainwater leaching under the prevailing meteorological conditions. The simulation period starts with the construction of the lysimeter in August 2007 and ends after 930 d in February 2010.

\subsection{Domain, Boundary and Initial Conditions}

The lysimeter consists of a 3-m deep pit with vertical walls and a square surface area with sides of $24 \mathrm{~m}$ length. The pit is sealed with a high-density plastic liner and drained by regularly spaced ( $2.5 \mathrm{~m}$ spacing) drainage pipes located at $2.8 \mathrm{~m}$ below ground level. The domain was simulated as a 2D slice orthogonal to the drainage pipes. Due to symmetry planes halfway between the drainage pipes, at the midpoint of the drainage pipes and at the lateral boundaries, the domain could be reduced to a 1-m wide and 3-m deep column.

Fig. 9: Lysimeter simulation domain and finite element representation.

The simulation domain and its finite element discretization are displayed in Fig. 9. The half circle at $x=0 \mathrm{~m}, z=-2.8 \mathrm{~m}$ represents part of the drainage pipe where a seepage face boundary according to Eq. (C.1) in Appendix C with $k_{s p}=10^{-4} \mathrm{~s}^{-1}$ was applied. At $z=0$, an atmospheric boundary according to Eq. (C.4) with $H_{c r i t}=-30 \mathrm{~m}, \xi=0.4 \mathrm{~s}^{-1}, H_{p_{o}}=0 \mathrm{~m}$ and $k_{p o}=10^{-4} \mathrm{~s}^{-1}$ was used. A zero-flux condition was employed for the remaining boundaries.

The upper part of the domain with predominantly vertical flow was discretized by a quadrilateral mesh with a vertical element size of $3 \times 10^{-3} \mathrm{~m}$ at the top boundary. The fine discretization was necessary to capture the sudden changes between infiltration and evaporation in the highly conductive sand. From $z=-2 \mathrm{~m}$ downwards, a triangular mesh with a compressed $z$-direction and local refinement around the seepage boundary was used. The initial pressure head at the start of the simulation was taken as $-1 \mathrm{~m}$. At the top boundary, equilibrium of the infiltrating and evaporating rainwater with atmospheric $\mathrm{CO}_{2}$ at $3.16 \times 10^{-4}$ 
398 atm and $\mathrm{O}_{2}$ at $1.99 \times 10^{-1}$ atm was assumed. The split-operator time step for alternations

399 between flow, transport and reaction calculations was set to $1 \mathrm{~d}$.

\subsection{Fertigation and Gypsum Amendment}

401 Further to its natural geochemical properties, residue sand in the $0-1.5 \mathrm{~m}$ depth interval was

402 amended with gypsum at a rate of $1 \%$ by weight. Furthermore, the top $0.2 \mathrm{~m}$ of the profile

403 received a one-off addition of $2.7 \mathrm{t} / \mathrm{ha}$ of inorganic fertiliser mix mainly comprised of di-

404 ammonium-phosphate (DAP), $\mathrm{K}_{2} \mathrm{SO}_{4}$ and $\mathrm{MgSO}_{4}$. Phosphate (from DAP) in contact with

405 gypsum is likely to reprecipitate as hydroxyapatite, which is why this mineral was included in

406 the simulations with an initial amount of 0 . This is also in agreement with observation in an

407 independent column experiment (data not shown).

408 The amendments were included in the model through additional equilibrium dissolution

409 reactions according to the reaction formulas, equilibrium constants and amounts listed in

$410 \quad$ Table 4. 


\begin{tabular}{|c|c|c|}
\hline $\begin{array}{l}\text { Mineral name } \\
\text { Reaction formula }\end{array}$ & $\begin{array}{l}\text { Equilibrium } \\
\text { constant }\end{array}$ & $\begin{array}{l}\text { Relative amount } \\
\left(\mathrm{mol}_{\text {soil }}{ }^{-1}\right)\end{array}$ \\
\hline $\begin{array}{l}\text { Gypsum }^{\text {a }} \\
\mathrm{CaSO}_{4}: 2 \mathrm{H}_{2} \mathrm{O}=\mathrm{Ca}^{+2}+\mathrm{SO}_{4}{ }^{-2}+2 \mathrm{H}_{2} \mathrm{O}\end{array}$ & $10^{-4.61 \mathrm{c}}$ & $1.10 \times 10^{-1}$ \\
\hline $\begin{array}{l}\mathrm{DAP}^{\mathrm{b}} \\
\left(\mathrm{NH}_{4}\right)_{2} \mathrm{HPO}_{4}=2 \mathrm{NH}_{4}^{+}+\mathrm{HPO}_{4}^{-2}\end{array}$ & $10^{0.3 \mathrm{~d}}$ & $5.67 \times 10^{-3}$ \\
\hline $\begin{array}{l}\text { Arcanite } \\
\mathrm{K}_{2} \mathrm{SO}_{4}=\mathrm{SO}_{4}^{-2}+2 \mathrm{~K}^{+}\end{array}$ & $10^{-1.776 \mathrm{e}}$ & $2.41 \times 10^{-3}$ \\
\hline $\begin{array}{l}\mathrm{MgSO}^{\mathrm{b}} \\
\mathrm{MgSO}_{4}=\mathrm{Mg}^{+2}+\mathrm{SO}^{-2}\end{array}$ & $10^{4.8781 \mathrm{f}}$ & $1.50 \times 10^{-4}$ \\
\hline $\begin{array}{l}\mathrm{MnSO}_{4}^{\mathrm{b}} \\
\mathrm{MnSO}_{4}=\mathrm{Mn}^{+2}+\mathrm{SO}_{4}^{-2}\end{array}$ & $10^{2.669 \mathrm{c}}$ & $1.42 \times 10^{-4}$ \\
\hline $\begin{array}{l}\mathrm{CuSO}^{\mathrm{b}} \\
\mathrm{CuSO}_{4}=\mathrm{Cu}^{+2}+\mathrm{SO}_{4}^{-2}\end{array}$ & $10^{3.01 \mathrm{c}}$ & $1.55 \times 10^{-4}$ \\
\hline $\begin{array}{l}\text { Zincosite }^{\mathrm{b}} \\
\mathrm{ZnSO}_{4}=\mathrm{Zn}^{+2}+\mathrm{SO}_{4}^{-2}\end{array}$ & $10^{3.01 \mathrm{c}}$ & $1.11 \times 10^{-3}$ \\
\hline $\begin{array}{l}\text { Borax }^{\text {b }} \\
\mathrm{Na}_{2}\left(\mathrm{~B}_{4} \mathrm{O}_{5}(\mathrm{OH})_{4}\right): 8 \mathrm{H}_{2} \mathrm{O}+2 \mathrm{H}^{+}=4 \mathrm{~B}(\mathrm{OH})_{3}+2 \mathrm{Na}^{+}+5 \mathrm{H}_{2} \mathrm{O}\end{array}$ & $10^{12.464 \mathrm{e}}$ & $2.62 \times 10^{-5}$ \\
\hline $\begin{array}{l}\text { Hydroxyapatite } \\
\mathrm{Ca}_{5}\left(\mathrm{PO}_{4}\right)_{3} \mathrm{OH}+4 \mathrm{H}^{+}=\mathrm{H}_{2} \mathrm{O}+3 \mathrm{HPO}_{4}^{-2}+5 \mathrm{Ca}^{+2}\end{array}$ & $10^{-3.421 \mathrm{~g}}$ & 0.00 \\
\hline
\end{tabular}

412 a applied to the top $1.5 \mathrm{~m},{ }^{\mathrm{b}}$ applied to the top $0.2 \mathrm{~m},{ }^{\mathrm{c}}$ minteq.dat, ${ }^{\mathrm{d}}$ calculated from solubility in pure water [71], 413 epfitzer.dat, ${ }^{\mathrm{f}}$ llnl.dat, ${ }^{\mathrm{g}}$ phreeqc.dat

414 As can be seen from Eq. (1), the rate of concentration changes due to the kinetic dissolution

415 of TCA and sodalite is dependent on the ratio of reactive surface to solution volume. In

416 unsaturated residue sand with an average moisture content of 0.2 , this ratio is approximately

41740 times larger than in the acid neutralization experiment. Therefore, the assumption of local

418 thermodynamic equilibrium was extended to TCA and sodalite. 


\subsubsection{Dynamic Water Balance}

421 Results of the dynamic water balance for the simulation period of $930 \mathrm{~d}$ starting on 1 August 4222007 are displayed in. The surface flux in (Fig. 10a) was normalized by the infiltrating area 423 and reflects the strong events during winter, which were immediately followed by marked 424 evaporation. Despite high potential evaporation during summer, actual evaporation was effectively shut down due to the limited water availability in the upper soil profile. Discharge in Fig. 10b was also normalized with respect to the infiltrating area for better comparability. The water infiltrated during the 2007 rainfall season at the beginning of the simulation reaches the drainage pipe after $60 \mathrm{~d}$. Before any discharge is produced, the domain below the drainage pipe was saturated. The initial filling of the lysimeter bottom during the first $60 \mathrm{~d}$ can be followed in the evolution of average moisture contents (Fig. 10c). The fast discharge recession leads to very low outflow rates during summer months. Despite the fully saturated lysimeter bottom, the moisture content frequently declined below a domain average of 0.15 during summers. This is also confirmed experimentally by in-situ moisture probes and neutron probe measurements.

Fig. 10: Dynamic water balance of lysimeter simulation with (a) surface flux $\left(\mathrm{mm} \mathrm{d}^{-1}\right)$, (b) drainage at the drainage pipe $\left(\mathrm{mm} \mathrm{d}^{-1}\right)$ and (c) average soil moisture content $\theta$.

437 Overall, the simulation of soil moisture in the lysimeter (Fig. 10) indicates very dry conditions throughout the entire simulation period. During summers, the water content

439 frequently decreased to values close to the residual (i.e., plant-unavailable) moisture content 440 in the upper metre of the profile. Despite low moisture contents, the average fluid pressure 441 did not drop below the permanent wilting point (PWP: $h=-15$ bar). However, near the surface the PWP was frequently reached. In addition, the sand contains only marginally more

443 water at -1 bar than at $-15 \mathrm{~m}$ due to the steep gradient of water retention $\frac{d h}{d \theta}$ (Fig. 5). Even 
444 during rainfall seasons, the moisture content hardly exceeded 0.2 in the upper $2.5 \mathrm{~m}$ of the

445 domain. Despite the poor water holding capacity of the sand, only about $46 \%$ of the total

446 rainfall left the lysimeter as drainage. The rest was lost by evaporation or stored in the

447 initially dry profile. Thus, the water supply alone imposed conditions that were challenging,

448 but not inhibiting, for plant growth in the lysimeter.

\subsubsection{Solution Chemistry}

450 Fig. 11 illustrates the evolution of vertical profiles of moisture content, $\mathrm{pH}$ and selected 451 solution element concentrations at the right domain boundary $(x=1 \mathrm{~m})$. Despite the local 452 outflow at the drainage pipe $(x=0 \mathrm{~m})$, only minor lateral variations of geochemistry and 453 moisture conditions were observed. Moisture content profiles show the development of the 454 groundwater table below the drainage pipe as response to the winter rainfall around $50 \mathrm{~d}$. The upper part of the soil column then dried out over summer until the beginning of the following rainy season. The $\mathrm{pH}$ profiles show a fast reduction of $\mathrm{pH}$ in the upper soil profile to about 11

457 from an initial value of 12.5 caused by gypsum dissolution and calcite precipitation. In the 458 lower profile below $-1.5 \mathrm{~m}$, the $\mathrm{pH}$ was governed by dissolved natron.

Fig. 11: Evolution of moisture content, pH and concentration of selected elements at the right domain boundary of the lysimeter simulation.

461 With the second winter's rainfall starting at around $300 \mathrm{~d}$, the $\mathrm{pH}$ reduced to values around 10 in the upper soil profile and with the third winter's rainfall in the entire profile. The initially high $\mathrm{Na}$ concentration from natron dissolution was flushed into the lower part of the

464 domain with the first rainfall. The second rainfall period almost completely removed $\mathrm{Na}$ from 465 the system, due to the comparatively low solubility of sodalite and analcime. Carbon, as 466 carbonate $\left(\mathrm{CO}_{3}^{-2}\right)$ from natron dissolution, immediately reprecipitated as calcite in the upper 467 part of the domain due to the large supply of $\mathrm{Ca}$ from gypsum dissolution. The remaining 468 carbon in the un-amended region of the domain was removed after approximately $50 \mathrm{~d}$. Ca 
concentrations show a complex pattern mainly governed by the solubility of calcite and

470 gypsum, both of which are controlled by $\mathrm{pH}$. The decrease in $\mathrm{Ca}$ at the top boundary during

471 the second and third rainfall period indicates complete removal of gypsum, which was not

472 observed in the field. This is most likely due to non-equilibrium of gypsum with the soil

473 solution as result of inhomogeneous amendment of the gypsum. During the following

474 evaporation events, the upwards flowing solution was concentrated due to the removal of

$475 \mathrm{H}_{2} \mathrm{O}$ at the surface. However, evaporation essentially stops during the dry season because of

476 low moisture contents at the surface. Sulphur, as sulphate $\left(\mathrm{SO}_{4}{ }^{-2}\right)$, behaved similarly to $\mathrm{Na}$ in

477 the region of gypsum amendment above $-1.5 \mathrm{~m}$. Its high initial concentration, resulting from

478 the equilibrium between gypsum and calcite, was flushed almost entirely within the first 300

479 d. Nitrogen $\left(\mathrm{N}(-3)\right.$ as sum of $\mathrm{NH}_{4}^{+}$and $\mathrm{NH}_{3}$ ) was decoupled from oxidized forms (e.g., $\left.\mathrm{NO}_{3}{ }^{-}\right)$

480 to avoid instantaneous conversion to $\mathrm{N}(+5)$. $\mathrm{N}(-3)$ concentrations are displayed representative

481 for the fertilizer elements copper $(\mathrm{Cu})$, zinc $(\mathrm{Zn})$ and boron $(\mathrm{B})$, which show very similar

482 concentration patterns. Their concentration ranges correspond to the amounts of the applied

483 fertilizer minerals (Table 4). The fertilizer elements were carried downwards through the soil

484 profile with the first winter rainfall, and with the second winter's rainfall, they were flushed

485 from the profile without significant retention. Due to high Ca concentrations the model

486 predicted reprecipitation of hydroxyapatite $\left(\mathrm{Ca}_{5}\left(\mathrm{PO}_{4}\right)_{3} \mathrm{OH}\right)$, which retains phosphate $(\mathrm{P})$ in

487 the profile. K concentrations were significantly retarded compared to nitrogen because of

488 temporary adsorption on the cation exchange sites. Magnesium $(\mathrm{Mg})$ shows a mixture of the

489 conservative transport pattern of nitrogen and the exchange pattern of K. High initial Al

490 concentrations in the lower half of the domain resulted from the dissolution of TCA, which is

491 enhanced by reprecipitation of $\mathrm{Ca}$ as calcite. In the gypsum-amended part of the soil, TCA

492 dissolution was inhibited by gypsum dissolution. Silica ( $\mathrm{Si}$ ) shows the same concentration 
493 pattern as chloride. Both elements were controlled by the dissolution of sodalite, which was 494 activated after the complete removal of TCA.

\subsubsection{Minerals}

496 Fig. 12 illustrates the evolution of the main mineral phases in residue sand. Muscovite and

497 analcime did not show any significant response towards leaching during the simulation period

498 and so are omitted in the figure. The other residue minerals show only minor changes in the 499 upper few decimetres of the domain. Gypsum was removed from the top $0.5 \mathrm{~m}$ after $3 \mathrm{y}$ of

500 rainfall. However, due to the equilibrium assumption, a considerable amount of gypsum in

501 the top $1.5 \mathrm{~m}$ instantaneously transformed into calcite, taking up most of the $\mathrm{CO}_{3}{ }^{-2}$ from

502 natron dissolution. Apart from this increase, calcite shows little response to leaching. Almost

503 half of the initial amount of TCA was immediately dissolved in the untreated residue sand

504 where Ca re-precipitated to calcite with the $\mathrm{CO}_{3}^{-2}$ from natron dissolution. This

505 transformation was suppressed by gypsum in the in the upper part of the domain. However,

506 the fertilizers in the top $0.2 \mathrm{~m}$ enhanced TCA dissolution. Leaching of the third rainfall

507 season around $700 \mathrm{~d}$ removed TCA from the top $0.2 \mathrm{~m}$. Sodalite shows no reaction towards

508 gypsum and fertilizer amendment. It was slowly leached from the first few centimetres of the

509 soil profile during the three simulated rain seasons once TCA and gypsum were removed.

510 Fig. 12: Evolution of the main minerals at the right domain boundary of the lysimeter simulation.

\section{$511 \quad 6.3 .4 \quad$ Cation Exchange}

512 The evolution of the exchange species is illustrated in Fig. 13. The initial exchanger

513 composition was dominated by $\mathrm{Na}$, which was replaced mainly by $\mathrm{Ca}$ during the course of

514 the simulation. Al is omitted in the figure due to insignificant adsorption in the high $\mathrm{pH}$

515 environment, where it was mainly present in anionic form as $\mathrm{Al}(\mathrm{OH})_{4}{ }^{-}$. At the transition from

516 the Na to Ca-dominated exchanger, adsorption of K, N(-3), Mg and Mn took place. Despite 
517 the higher affinity of standard exchangers for divalent ions, $\mathrm{K}$ was the most adsorbed

518 fertilizer element. This is because of its higher concentration compared to divalent fertilizer

519 elements and its large affinity relative to other monovalent fertilizer elements. $\mathrm{N}(-3)$ as $\mathrm{NH}_{4}^{+}$,

520 which was retained in the upper part of the profile during the first summer, was almost

521 completely removed during the second rainfall period. The low adsorption of N(-3) resulted

522 from its speciation into uncharged $\mathrm{NH}_{3}$ at $\mathrm{pH}$ values above 9. The amount of adsorbed $\mathrm{Mg}$,

523 which is representative for the adsorption pattern of Mn (maximum adsorbed amount $1.5 \times$

$52410^{-5} \mathrm{~mol}_{\text {soil }}{ }^{-1}$ ), increased after $400 \mathrm{~d}$. The adsorption of zinc and copper was insignificant due

525 to low solution concentrations (maximum adsorbed amounts $10^{-8} \mathrm{~mol}_{\text {soil }^{-1}}$ and $3 \times 10^{-11} \mathrm{~mol}$

$5261_{\text {soil }}^{-1}$, respectively).

527 Fig. 13: Evolution of the exchanger composition at the right domain boundary of the lysimeter simulation.

528 Overall, the predicted geochemical conditions in the lysimeter were still unfavourable for

529 plant growth after $3 \mathrm{y}$, both in terms of water availability and quality. Even though the main

530 soluble ions $\mathrm{Na}^{+}$and $\mathrm{SO}_{4}{ }^{-2}$ were flushed from the system, a $\mathrm{pH}$ of 10 was maintained. The

531 plant nutrient status was not sustainably improved by fertilizer amendment. Only K was

532 significantly retained by initially Na-filled adsorption sites. Adsorption of other fertilizer

533 cations including $\mathrm{NH}_{4}{ }^{+}$was insignificant due to (i) their low concentrations compared to the

534 major solutions ions $\mathrm{Na}$ and $\mathrm{Ca}$, (ii) their speciation into neutral or negatively charged ions at

535 high $\mathrm{pH}$, and (iii) the low exchange capacity of residue sand. The chromatographic sequence

536 from a Na-dominated exchanger through the temporary adsorption of fertilizer cations to a

537 Ca-dominated system can be interpreted as a snowplough [72-74]. The buffering minerals,

538 TCA, sodalite and calcite that stabilize the $\mathrm{pH}$ around 10 were removed from the top few

539 centimetres of the profile. As intended by the gypsum amendment, solution alkalinity was

540 converted to calcite $[75,76]$. This procedure, however, did not remove the alkalinity from the

541 system converted it into solid form and prevents the removal of TCA [77]. 


\section{Simulation of Surface Cover for Storage Facilities}

543 In order to evaluate the performance of fertigated and gypsum-amended residue sand as a

544 surface cover for storage facilities, the hydrogeochemical model was applied to a stratum of

545 sand overlaying low permeability residue mud. Apart from the domain geometry and

546 discretization, the hydrological and geochemical conditions of the lysimeter simulation were

547 adopted including fertigation and gypsum amendment. In contrast to the lysimeter with

548 predominantly vertical flow, the development of a water table at the border to the residue

549 mud introduces a considerable horizontal flow component.

\subsection{Domain, Boundary and Initial Conditions}

551 The simulation represents a 3-m thick by $100-\mathrm{m}$ wide layer of residue sand on top of a

552 storage impoundment. Due to symmetry across the centre line, the actual simulation domain

553 was confined to a slice of the cover layer from $x=0 \mathrm{~m}$ to $x=50 \mathrm{~m}$ with a symmetry

554 boundary at the right hand side border of the domain. The domain was represented by 10,829

555 computational nodes. For enhanced lateral drainage, the cover layer was conceptualized with

556 a slope of $1.74 \%$. Water losses at the interface to the residue mud at the domain bottom were

557 approximated by a constant flux of $8.3 \times 10^{-7} \mathrm{~m} \mathrm{~s}^{-1}$ in water-saturated conditions and zero

558 flux otherwise. The magnitude of this deep percolation was taken as the saturated hydraulic

559 conductivity of red mud [3], in which case the flux corresponds to gravity-driven drainage.

560 The left hand side of the domain was represented by a seepage face boundary according to

561 Eq. (C.1) with a stiff-spring constant of $k_{s p}=10^{-3} \mathrm{~s}^{-1}$. Atmospheric forcing of the system was

562 imposed via an atmospheric boundary condition at the top of the domain. In order to predict

563 the evolution of the sand cover for $5 \mathrm{y}$, the measured meteorological time series of $3 \mathrm{y}$ were

564 repeatedly applied to the soil surface. 


\subsubsection{Dynamic Water Balance}

567 The dynamic water balance of the surface cover simulation is illustrated in Fig. 14. For better

568 comparability with the lysimeter simulation (Fig. 10), the $y$-axis scaling was retained.

569 Compared to the lysimeter simulation the surface cover exhibits much larger water storage capacity and slower recession of discharge during dry periods due to impeded drainage (Fig. 14b). As in Fig. 10, the drainage flux was normalized to the inflow area for comparability. At the beginning of the simulation period, a perched water table evolved at the border to the

573 low-permeability mud. Due to this water table, the average soil moisture (Fig. 14c) was at 574 much higher levels (0.2-0.3) compared to the lysimeter simulation.

Fig. 14: Dynamic water balance of surface cover simulation, with (a) surface flux $\left(\mathrm{mm} \mathrm{d}^{-1}\right)$, (b) drainage $\left(\mathrm{mm} \mathrm{d}^{-1}\right)$ and (c) average soil moisture content $\theta$.

\subsubsection{Solution Chemistry}

578 Time-dependent profiles of normalized soil moisture, $\Theta=\frac{\theta-\theta_{r}}{\theta_{s}-\theta_{r}}$, selected total element

579 concentrations and $\mathrm{pH}$ are displayed in Fig. 15 with different scales for the $x$ - and $y$-axes.

580 Different colour scales were used for the plots from 1 to $50 \mathrm{~d}$ and from 400 to $1825 \mathrm{~d}$ because

581 the low fertilizer concentrations after the first rainfall period would otherwise be

582 indistinguishable in the later profiles. Display times were selected during the first rainfall

583 period ( $1-50 \mathrm{~d})$, in the middle of the second rainfall period ( $400 \mathrm{~d})$, after the third rainfall

584 period (1000 d) and at the end of $5 \mathrm{y}$ of atmospheric leaching (1825 d).

585 Normalized water contents illustrate the build-up of soil moisture at the border of the residue

586 mud and the evolution of a perched water table. The results at 400 and $1000 \mathrm{~d}$ show water

587 table fluctuations from winter to summer. 

cover simulation at $1,20,50,400,600$ and $1825 \mathrm{~d}$.

590 Until the last profile at $1825 \mathrm{~d}$, Ca that mainly originates from gypsum and TCA dissolution

591 did not enter the saturated zone. Declining concentrations at the top of the domain indicate

592 complete removal of gypsum and TCA. Na was flushed from the unsaturated zone with the

593 first rainfall event. Due to the velocity field in the saturated groundwater lens, concentrations

594 were more persistent towards the right hand side of the domain. However, after the third

595 rainfall season $(1000 \mathrm{~d})$ most of the $\mathrm{Na}$ has been removed. $\mathrm{N}(-3)$ is representative for all

596 fertilizer elements besides K. Through dilution and dispersion, concentrations decreased with

597 the first infiltration water. During the second rainfall period around $400 \mathrm{~d}$, the fertilizers were

598 removed from the unsaturated zone. However, they remained in the groundwater lens at

599 roughly a tenth of their original concentration. Fertilizer concentrations decreased further

600 during the third rainfall season until they were removed completely after $5 \mathrm{y}$ of leaching. The

601 behaviour of K, the most adsorbing element, was very similar to N(-3). As result of the

602 exchange process, however, its removal was delayed compared to the other fertilizer

603 elements. During the first rainfall period, the $\mathrm{pH}$ behaved similarly to the lysimeter

604 simulation because of essentially 1D flow. After the perched water table has established, two

$605 \mathrm{pH}$ regions were separated by the line of the groundwater table in moist conditions. The $\mathrm{pH}$

606 in the saturated region was persistent until it was eventually leached to pore water levels in

607 the unsaturated zone after $5 \mathrm{y}$. In the profiles at 1000 and $1825 \mathrm{~d}$ the removal of gypsum and

608 TCA at the top of the domain decreased the $\mathrm{pH}$ to around 9.

\section{$609 \quad 7.2 .3 \quad$ Minerals}

610 The evolution of the main minerals in the surface cover is illustrated in Fig. 16. During 5 y of

611 rainfall, gypsum was removed from the top metre of the profile. In this zone, calcite showed

612 hardly any response to leaching. However, additional precipitation was predicted at the lower 
613 boundary of the gypsum-amended region and in the saturated zone. TCA was removed from

614 the top $0.5 \mathrm{~m}$ and from the saturated zone, while sodalite was only removed from the top few

615 decimetres. Exchange processes are dominated by Na-Ca exchange, and are omitted since the

616 results are similar to those for the lysimeter.

617 In summary, the results show that water availability was improved in the surface cover by the

618 formation of a perched groundwater table. Waterlogged conditions with evaporation-induced

619 salt accumulation at the soil surface [78-80] were avoided by the slope of the underlying low-

620 permeability mud and lateral drainage. Due to its large water volume, the saturated zone

621 acted as a buffer for infiltrating solutes and retained fertilizer ions. However, enhanced water

622 retention also retained adverse soil properties such as high $\mathrm{pH}$ and $\mathrm{Na}$ concentrations, which

623 decreased the efficiency of natural leaching.

624 Fig. 16: Evolution of the main minerals of the surface cover simulation for 1 and $1825 \mathrm{~d}$.

6258 General Discussion

\subsection{Model Uncertainties}

627 The model for mineral reactions in bauxite residue sand comprises large uncertainties, even

628 though all components of the mineral assembly have been previously identified in residue of different origins $[30,34,41,81]$. The mineral assembly as deduced from acid neutralization

630 alone is not unique and other combinations of minerals may reproduce $\mathrm{pH}$ buffering equally

631 well. Sodalite and additional amounts of natron, for instance, yield excellent agreement with

632 acid neutralization at $96 \mathrm{~h}$. However, this would require the kinetic dissolution of natron at a

633 timescale of days, which is not plausible unless it is partially occluded within the profile. In

634 order to increase the reliability of the predictions, detailed quantification of the reactive

635 minerals specifically for Pinjarra residue sand would be required. Furthermore, equilibrium 
constants vary widely among authors and databases, particularly for different forms of

637 tricalcium aluminates but also for muscovite and analcime. Measurements of the stoichiometry and solubility of reactive minerals on phases isolated from the residue would

639 be desirable. This is also important because most reactive minerals form during the refining

640 process, so that their reactivity and stoichiometry depends on the bauxite source and

641 processing conditions [32, 33, 39, 82, 83]. The fact that Khaitan et al. [34] attribute the $\mathrm{pH}$

642 buffering capacity of residue from Jamaican bauxite mainly to TCA and calcite whereas

643 Menzies et al. [41] and Snars and Gilkes [30] hold mainly sodalite and calcite responsible for

$644 \mathrm{pH}$ control indicates the large uncertainty in the recent literature. In the mineral assembly

645 determined in this study, both phases contribute to $\mathrm{pH}$ buffering in roughly equal parts.

646 Acknowledging the large uncertainties, the derived mineral composition can be regarded as a surrogate for major geochemical properties such as $\mathrm{pH}$, electrical conductivity and $\mathrm{Na}$ concentrations. Concentrations of elements that are not components of an included mineral, such as iron, $\mathrm{Mg}$ and titanium (Ti), cannot be predicted. $\mathrm{pH}$-dependent variable charge adsorption sites to the overall adsorption characteristics of

652 residue sand. Menzies et al. [41] measured the effective exchange capacity of seawater neutralized residue sand as $18.6 \mathrm{cmol} \mathrm{kg}_{\text {solid }}{ }^{-1}$ from which they attributed $6 \mathrm{cmol} \mathrm{kg}_{\text {solid }}{ }^{-1}$ to variable charge. These values exceed the cation exchange capacity measured in this study by a factor of 10-20. However, both previous studies rely on compulsive exchange of $\mathrm{K}^{+}$with $\mathrm{NH}_{4}{ }^{+}$. As shown in Fig. 4b, considerable amounts of $\mathrm{K}$ are released by mineral dissolution.

657 Therefore, K concentrations cannot be considered to result solely from exchange processes, 658 which may lead to an overestimation of the effective exchange capacity. The presumed $\mathrm{pH}-$ 659 dependency of the exchange sites may in fact reflect the solubility of the source mineral (e.g., 660 muscovite). On the other hand, the effective exchange capacity in our study may have been 
661 reduced by the washing procedure, particularly through the removal of surface aluminous and

662 ferric oxides that contribute to variable charge adsorption sites. Nevertheless, we employ the

663 lower value of cation exchange capacity on washed residue since it gives a more conservative

664 estimate of nutrient retention. Because $\mathrm{pH}$ levels during the simulations were well above the

665 point of zero charge of ferrous and aluminous oxides [84, 85], charge characteristics are not

666 expected to change significantly. This justifies the use of a simple exchange model for

667 adsorption. However, the adsorption behaviour of cations onto zeolites such as sodalite is

668 influenced by the window size of their cage structure [86-90]. Thus, the applicability of

669 standard affinity constants for the simulation of cation exchange remains uncertain [91].

670 The dynamic water balance is regarded as relatively reliable since the parameters for soil

671 moisture movement are directly measured or derived from measurements according to

672 standard procedures (e.g., water retention).

673 An obvious weakness of the simulations is the lack of in-depth model validation due to the

674 scarcity of analytical data.

\subsection{Implications for Bauxite Residue Management}

676 Despite the model uncertainties, the main results are plausible and consistent with

677 observations. Because the model is adapted to the geochemical and meteorological conditions

678 at the Pinjarra refinery, findings are site-specific but can be generalized to residue sand with

679 similar properties and in comparable climatic conditions.

680 The lysimeter simulation illustrates the poor water retention in the residue sand with low

681 plant-available soil moisture content. Thus in well-drained systems water availability is a

682 limiting factor for plant growth. The simulation of the cover layer shows that the moisture

683 status in residue sand can be improved by the appropriate design of the horizontal distance 
684 between drains, the thickness of the cover layer and its slope. If these parameters are not

685 chosen carefully, for example if the distance between drains is too large, waterlogged

686 conditions with adverse effects on plant growth may result (simulation results not shown).

687 The development of a shallow water table increases evaporation losses during the summer

688 months. Although not observed in our simulations, this may lead to salt accumulation at the

689 soil surface [e.g., 78, 79]. The amendment of residue sand with fine-textured residue mud

690 would improve the soil water retention but at the same time worsens the geochemical

691 properties through enhanced $\mathrm{pH}$ buffering [92]. Compared to the hydrological situation, the

692 geochemical properties of the residue sand are seen as more severe constraints for plant

693 growth. Mineral reactions in amended fresh residue sand are governed by the initial

694 dissolution of natron and gypsum, where $\mathrm{Ca}$ and $\mathrm{CO}_{3}^{-2}$ precipitate as calcite while the soluble

$695 \mathrm{Na}_{2} \mathrm{SO}_{4}^{-2}$ is flushed. Even though gypsum amendment reduces the solution $\mathrm{pH}$ to 10 , leaching

696 of TCA and therefore the sustainable decrease of $\mathrm{pH}$ buffering in the sand is inhibited. From

697 the main buffering minerals, TCA and sodalite are very resistant to rainwater leaching due to

698 their low solubility. Efficient retention of fertilizers is prevented by (i) the low cation

699 exchange capacity of residue sand, (ii) competition with high levels of $\mathrm{Ca}$ and $\mathrm{Na}$ for

700 exchange sites, and (iii) the speciation of fertilizer elements into uncharged or negative ions

701 at elevated $\mathrm{pH}\left(\right.$ e.g., $\mathrm{NH}_{3}$ ). Therefore, the addition of fertilizers to gypsum-amended fresh

702 residue sand only temporarily improves the plant nutrient status. Natural attenuation of

703 gypsum-amended and fertigated residue sand through atmospheric leaching is not a viable

704 long-term option to improve the hydrogeochemical properties for establishing a sustainable

705 vegetation cover.

706 Instead, we propose a comprehensive treatment scheme that aims at improving all major

707 aspects of soil fertility: 
1. Removal of most soluble mineral fractions - e.g., through seawater neutralization [5, $41,93,94]$ - to decrease the solid $\mathrm{pH}$ buffering capacity and attenuate the competition with fertilizer ions for exchange sites;

2. Amendment with a fine textured mineral soil (not residue mud) to improve water retention and cation exchange capacity;

3. Adaption of surface cover dimensions to the hydraulic properties of the substrate with regularly spaced drains to improve the water balance;

4. Amendment with organic fertilizer to establish a natural microbial community, increase the adsorption capacity [6, 8, 95-97]; and

5. Application of inorganic fertilizers $[10,12,16,17,95,98]$ to improve the plant nutrient status.

\section{Conclusions}

720 We present the application of a software coupling of COMSOL and IPhreeqc for interactions

721 of comprehensive geochemical reactions and 2D variably saturated soil moisture movement

722 to evaluate the environmental behaviour of bauxite refining residue sand. The main findings

723 of the simulations are:

- In well-drained residue sand, the average moisture content drops below 0.1 for extended periods during summer, which poses limitations to plant growth.

- By adapting the dimensions and drainage of residue storage facilities to the hydraulic properties of the cover material (e.g., mixtures of sand and clay), a plant-suitable moisture content can be maintained also during the dry summer months.

- Nonrecurring fertilizer application on fresh residue sand does not alter the long-term plant nutrient status due to low cation exchange capacity, competition with predominant solution ions and speciation into neutral or negative form. 
- Gypsum amendment ameliorates the $\mathrm{pH}$ to around 10 but suppresses the dissolution of TCA and therefore hampers the sustainable leaching of solid alkalinity.

Thus, we conclude that gypsum-amendment and application of inorganic fertilizers alone does not sufficiently improve the geochemical conditions in residue sand to promote a vigorous and sustainable vegetation cover. Since the minerals in residue sand have a very high buffering capacity and annual recharge rates in southwest Western Australia are low, natural attenuation of the sand's $\mathrm{pH}$ via rainfall leaching is predicted to be in the order of tens of years. For the successful revegetation of residue storage facilities all aspects of soil fertility need to be addressed before residue sand can serve as valuable medium for plant growth. A logical step for future model development would be the incorporation of biological transformations by plants and soil microbes.

\section{Acknowledgments}

The authors acknowledge Chanelle Carter, whose contributions benefitting this study were sadly cut short by her untimely death. Partial financial support was provided by ALCOA World Alumina Australia, Pty. Ltd.

\section{References}

[1] IAI International Aluminium Institute, 2011. Alumina production, Available from: http://world-aluminium.org/?pg=statistics, accessed 15.04.2011.

[2] CSIRO, 2011. Bauxite residue database, Available from: http://www.csiro.au/products/Bauxite-residue-database.html, accessed 15.04.2011.

[3] J.B. Wehr, I. Fulton, N.W. Menzies, Revegetation strategies for bauxite refinery residue: A case study of Alcan Gove in Northern Territory, Australia, Environ Manage, 37 (2006) 297-306. 
[4] ALCOA World Alumina, 2011. Dry stacking of bauxite residue, Available from: http://www.alcoa.com/global/en/environment/pdf/Dry_Stacking_Case_Study1.pdf, accessed 15.04.2011.

[5] G. Power, M. Gräfe, C. Klauber, 2009. Review of current bauxite residue management, disposal and storage: Practises, engineering and science. CSIRO.

[6] R.G. Courtney, S.N. Jordan, T. Harrington, Physico-chemical changes in bauxite residue following application of spent mushroom compost and gypsum, Land Degradation \& Development, 20 (2009) 572-581.

[7] R.G. Courtney, J.P. Timpson, Reclamation of fine fraction bauxite processing residue (red mud) amended with coarse fraction residue and gypsum, Water, Air, and Soil Pollution, 164 (2004) 91-102.

[8] R.G. Courtney, J.P. Timpson, Nutrient status of vegetation grown in alkaline bauxite processing residue amended with gypsum and thermally dried sewage sludge - A two year field study, Plant and Soil, 266 (2004) 187-194.

[9] L.R. Hossner, R.H. Loeppert, 1984. Reclamation and vegetation of bauxite residue, Project Report to Aluminum Company of America. Soil \& Crop Science Department Texas A\&M University: Point Comfort, Texas.

[10] C. Thiyagarajan, I.R. Phillips, B. Dell, R.W. Bell, Micronutrient fractionation and plant availability in bauxite-processing residue sand, Australian Journal of Soil Research, 47 (2009) 518-528.

[11] H.J. Woodard, L. Hossner, J. Bush, Ameliorating caustic properties of aluminum extraction residue to establish a vegetative cover, Journal of Environmental Science and Health - Part A Toxic/Hazardous Substances and Environmental Engineering, 43 (2008) 1157-1166.

[12] R. Courtney, G. Mullen, T. Harrington, An evaluation of revegetation success on bauxite residue, Restoration Ecology, 17 (2009) 350-358.

[13] M.J. Gherardi, Z. Rengel, Bauxite residue sand has the capacity to rapidly decrease availability of added manganese, Plant and Soil, 234 (2001) 143-151.

[14] I.R. Phillips, C. Chen, Surface charge characteristics and sorption properties of bauxite-processing residue sand, Australian Journal of Soil Research, 48 (2010) 7787.

[15] B.E.H. Jones, R.J. Haynes, Bauxite Processing Residue: A Critical Review of Its Formation, Properties, Storage, and Revegetation, Critical Reviews in Environmental Science and Technology, 41 (2011) 271-315.

[16] C.R. Chen, I.R. Phillips, L.L. Wei, Z.H. Xu, Behaviour and dynamics of diammonium phosphate in bauxite processing residue sand in Western Australia-II. Phosphorus fractions and availability, Environmental Science and Pollution Research, (2009) 1-9.

[17] C.R. Chen, I.R. Phillips, L.L. Wei, Z.H. Xu, Behaviour and dynamics of diammonium phosphate in bauxite processing residue sand in Western Australia-I. NH3 
volatilisation and residual nitrogen availability, Environmental Science and Pollution Research, (2009) 1-12.

[18] P.C. Lichtner, Continuum model for simultaneous chemical-reactions and masstransport in hydrothermal systems, Geochim Cosmochim Ac, 49 (1985) 779-800.

[19] P.C. Lichtner, Continuum formulation of multicomponent-multiphase reactive transport, in: P.C. Lichtner, C.I. Steefel, E.H. Oelkers (Eds.) Reactive Transport in Porous Media, Mineralogical Society of America, Washington DC, 1996, pp. 1-81.

[20] C.I. Steefel, New directions in hydrogeochemical transport modeling: Incorporating multiple kinetic and equilibrium reaction pathways, in: L.R. Bentley, J.F. Sykes, C.A. Brebbia, W.G. Gray, G.F. Pinder (Eds.) Computational Methods in Water Resources, Balkema, Rotterdam, 2000, pp. 331-338.

[21] C.I. Steefel, D.J. DePaolo, P.C. Lichtner, Reactive transport modeling: An essential tool and a new research approach for the Earth sciences, Earth Planet Sc Lett, 240 (2005) 539-558.

[22] B. Hanson, J.W. Hopmans, J. Šimůnek, Leaching with subsurface drip irrigation under saline, shallow groundwater conditions, Vadose Zone Journal, 7 (2008) 810818.

[23] B.R. Hanson, J. Šimůnek, J.W. Hopmans, Evaluation of urea-ammonium-nitrate fertigation with drip irrigation using numerical modeling, Agricultural Water Management, 86 (2006) 102-113.

[24] A.I. Gärdenäs, J.W. Hopmans, B.R. Hanson, J. Šimůnek, Two-dimensional modeling of nitrate leaching for various fertigation scenarios under micro-irrigation, Agricultural Water Management, 74 (2005) 219-242.

[25] J. Šimůnek, D. Jacques, M.T. van Genuchten, D. Mallants, Multicomponent geochemical transport modeling using HYDRUS-1D and HP1, Journal of the American Water Resources Association, 42 (2006) 1537-1547.

[26] J. Šimůnek, S.A. Bradford, Vadose zone modeling: Introduction and importance, Vadose Zone Journal, 7 (2008) 581-586.

[27] L. Wissmeier, D.A. Barry, Reactive transport in unsaturated soil: Comprehensive modelling of the dynamic spatial and temporal mass balance of water and chemical components, Advances in Water Resources, 31 (2008) 858-875.

[28] L. Wissmeier, A. Brovelli, C. Robinson, F. Stagnitti, D.A. Barry, Pollutant fate and transport in the subsurface, in: Modelling of Pollutants in Complex Environmental Systems, ILM Publications, 2009, pp. 99-143.

[29] D.L. Parkhurst, C.A.J. Appelo, 1999. User's guide to PHREEQC (version 2): A computer program for speciation, batch-reaction, one-dimensional transport, and inverse geochemical calculations. U.S. Geological Survey: Denver, Colorado.

[30] K. Snars, R.J. Gilkes, Evaluation of bauxite residues (red muds) of different origins for environmental applications, Applied Clay Science, 46 (2009) 13-20. 
[31] S. Taylor, N. Pearson, 2001. Properties of Bayer process solids from Alcoa WA refineries and their component minerals. ALCOA World Alumina: Technology Delivery, Internal Report.

[32] B.I. Whittington, T.M. Fallows, M.J. Willing, Tricalcium aluminate hexahydrate (TCA) filter aid in the Bayer industry: factors affecting TCA preparation and morphology, International Journal of Mineral Processing, 49 (1997) 1-29.

[33] B.I. Whittington, C.M. Cardile, The chemistry of tricalcium aluminate hexahydrate relating to the Bayer industry, International Journal of Mineral Processing, 48 (1996) 21-38.

[34] S. Khaitan, D.A. Dzombak, G.V. Lowry, Chemistry of the acid neutralization capacity of bauxite residue, Environmental Engineering Science, 26 (2009) 873-881.

[35] G.E. Ho, W.A. Robertson, G.I. Roach, A. Antonovsky, Morphological study of bayer process desilication product and its application to laboratory and plant digests, Industrial \& Engineering Chemistry Research, 31 (1992) 982-986.

[36] J.L. Lowe, R.D. Hart, P.G. Smith, A.L. Rohl, G.M. Parkinson, Morphology and crystllinity: Insight into the mechanism of growth of DSP, in: 7th International Alumina Quality Workshop, CSIRO Minerals, Waterford, WA, Western Australia, 2005, pp. 168-173.

[37] T. Picaro, B. Pei, A.R. Kane, M.R. Thornber, A.B. Fletcher, Separation and mineralogical analysis of bayer red mud, Developments in Chemical Engineering and Mineral Processing, 10 (2002) 475-489.

[38] P.G. Smith, R. Pennifold, T. Lwin, A. Kane, The composition of DSP formed under predesilication and high temperature Bayer digestion conditions, in: Light Metals: Proceedings of Sessions, TMS Annual Meeting (Warrendale, Pennsylvania), 2001, pp. 5-11.

[39] B. Whittington, T. Fallows, Formation of lime-containing desilication product (DSP) in the Bayer process: factors influencing the laboratory modelling of DSP formation, Hydrometallurgy, 45 (1997) 289-303.

[40] B.I. Whittington, B.L. Fletcher, C. Talbot, The effect of reaction conditions on the composition of desilication product (DSP) formed under simulated Bayer conditions, Hydrometallurgy, 49 (1998) 1-22.

[41] N.W. Menzies, I.M. Fulton, R.A. Kopittke, P.M. Kopittke, Fresh water leaching of alkaline bauxite residue after sea water neutralization, Journal of Environmental Quality, 38 (2009) 2050-2057.

[42] W. Stumm, J.J. Morgan, Aquatic Chemistry: Chemical Equilibria and Rates, Wiley, New York, 1996.

[43] J. Doherty, 2004. PEST model-independent parameter estimation, User manual: 5th edition. Watermark Numerical Computing: Australia.

[44] M.R. Thornber, C.A. Hughes, The alkalinity of residues from Alcoa of Australia Limited's refineries of south-west Australia, in: International Bauxite Tailings 
Workshop, Executive Management Services, Perth Western Australia, 1992, pp. 136147.

[45] J. Schott, O.S. Pokrovsky, E.H. Oelkers, The link between mineral dissolution/precipitation kinetics and solution chemistry, in: E.H. Oelkers, J. Schott (Eds.) 19th Annual V M Goldschmidt Conference, Mineralogical Soc Amer, Davos, Switzerland, 2009, pp. 207-258.

[46] N. Komada, E.F. Westrum, B.S. Hemingway, M.Y. Zolotov, Y.V. Semenov, I.L. Khodakovsky, L.M. Anovitz, Thermodynamic properties of sodalite at temperatures from $15 \mathrm{~K}$ to $1000 \mathrm{~K}$, Journal of Chemical Thermodynamics, 27 (1995) 1119-1132.

[47] R.L. Cooley, R.L. Naff, Regression modeling of ground-water flow, in: U.S. Geological Survey open-file report USGS-TWRI Book 3 Chapter B4, USGS Denver, CO, 1990, pp. 85-180.

[48] C. Amrhein, D.L. Suarez, Procedure for determining sodium-calcium selectivity in calcareous and gypsiferous soils, Soil Science Society of America Journal, 54 (1990) 999-1007.

[49] J.H. Grove, C.S. Fowler, M.E. Sumner, Determination of the charge character of selected acid soils, Soil Science Society of America Journal, 46 (1982) 32-38.

[50] D.L. Sparks, J.M. Bartels, J.M. Bigham, Part 3: Chemical Methods, Soil Science Scociety of America, Madison, Wisconsin, 1996.

[51] AFNOR, NF X31-130: Détermination de la capacité d'échange cationique (CEC) et des cations extractibles, in, Paris, 1999.

[52] C.A.J. Appelo, D. Postma, Geochemistry, Groundwater and Pollution, 2nd ed., Balkema, Leiden, Netherlands, 2005.

[53] I.B. Oliveira, A.H. Demond, A. Salehzadeh, Packing of sands for the production of homogeneous porous media, Soil Science Society of America Journal, 60 (1996) 4953.

[54] Y. Mualem, New model for predicting hydraulic conductivity of unsaturated porous media, WRR, 12 (1976) 513-522.

[55] M.T. van Genuchten, Closed-form equation for predicting the hydraulic conductivity of unsaturated soils, Soil Science Society of America Journal, 44 (1980) 892-898.

[56] J. Šimůnek, M. Šejna, H. Saito, M. Sakai, M.T. van Genuchten, 2009. The HYDRUS1D software package for simulating the movement of water, heat, and multiple solutes in variably saturated media, Version 4.0. Department of Environmental Sciences, University of California Riverside: Riverside, California.

[57] M. Abramowitz, A.I. Stegun, Handbook of Mathematical Functions with Formulas, Graphs, and Mathematical Tables, United States Department of Commerce, National Bureau of Standards, Washington DC, 1972.

[58] O.A. Cirpka, P.K. Kitanidis, Numerical evaluation of solute dispersion and dilution in unsaturated heterogeneous media, WRR, 38 (2002). 
913

914

915

916

917

918

919

920

921

922

923

924

925

926

927

928

929

930

931

932

933

934

935

936

937

938

939

940

941

942

943

944

945

946

947

948

949

950

951

[59] T. Sato, H. Tanahashi, H.A. Loaiciga, Solute dispersion in a variably saturated sand, WRR, 39 (2003).

[60] D. Schulze-Makuch, Longitudinal dispersivity data and implications for scaling behavior, Ground Water, 43 (2005) 443-456.

[61] COMSOL Multiphysics ${ }^{\circledR}, 2011$. Available from: http://www.comsol.com/, accessed 15.04.2011.

[62] S.R. Charlton, D.L. Parkhurst, Modules based on the geochemical model PHREEQC for use in scripting and programming languages, Computers \& Geosciences, In Press, Accepted Manuscript (2010).

[63] MATLAB ${ }^{\circledR}, 2011$. The MathWorks ${ }^{\circledR}$, Available from: http://www.mathworks.com/, accessed 15.04.2011.

[64] H. Prommer, D.A. Barry, G.B. Davis, A one-dimensional reactive multi-component transport model for biodegradation of petroleum hydrocarbons in groundwater, Environmental Modelling \& Software, 14 (1999) 213-223.

[65] H. Prommer, D.A. Barry, C. Zheng, MODFLOW/MT3DMS-based reactive multicomponent transport modeling, Ground Water, 41 (2003) 247-257.

[66] X. Mao, H. Prommer, D.A. Barry, C.D. Langevin, B. Panteleit, L. Li, Threedimensional model for multi-component reactive transport with variable density groundwater flow, Environmental Modelling \& Software, 21 (2006) 615-628.

[67] L. Wissmeier, D.A. Barry, Simulation tool for variably saturated flow with comprehensive geochemical reactions in two- and three-dimensional domains, Environmental Modelling \& Software, 26 (2011) 210-218.

[68] E.P. Hodgkin, B.H. Hamilton, Fertilizers and eutrophication in Southwestern Australia - Setting the scene, Fertilizer Research, 36 (1993) 95-103.

[69] J. Eastham, 2005. A simple water balance approach for estimating the amount of leachate from bauxite residue storage areas. ALCOA World Alumina, Internal Report.

[70] I.R. Phillips, 2009. Guidelines for constructing a field lysimeter to monitor waternutrient-plant dynamics. ACOA World Alumina, Mining Environmental Group, Internal Report.

[71] G.H. Buchanan, G.B. Winner, The solubility of mono and diammonium phosphate, Journal of Industrial and Engineering Chemistry, 12 (1920) 448-451.

[72] K. Bajracharya, D.A. Barry, Analysis of one-dimensional multispecies transport experiments in laboratory soil columns, Environment International, 21 (1995) 687691.

[73] D.A. Barry, J.L. Starr, J.Y. Parlange, R.D. Braddock, Numerical analysis of the snowplow effect, Soil Science Society of America Journal, 47 (1983) 862-868.

[74] C.A.J. Appelo, Multicomponent ion exchange and chromatography in natural systems, in: P.C. Lichtner, C.I. Steefel, E.H. Oelkers (Eds.) Reactive Transport in Porous Media, Mineralogical Society of America, Washington, 1996, pp. 193-227. 
[75] J.W.C. Wong, G.E. Ho, Effects of gypsum and sewage sludge amendment on physical properties of fine bauxite refining residue, Soil Science, 152 (1991) 326-332.

[76] J.W.C. Wong, G.E. Ho, Use of waste gypsum in the revegetation on red mud

[77] R. Mattinson, 2003. Assessment of amendments for sand residue neutralization, Residue Neutralization. ALCOA World Alumina: Research and Development, Internal Report.

[78] D.A. Rose, F. Konukcu, J.W. Gowing, Effect of watertable depth on evaporation and salt accumulation from saline groundwater, Australian Journal of Soil Research, 43 (2005) 565-573.

[79] E. Shimojima, R. Yoshioka, I. Tamagawa, Salinization owing to evaporation from bare-soil surfaces and its influences on the evaporation, J Hydrol, 178 (1996) 109136.

[80] C.E. Desborough, A.J. Pitman, P. Iranneiad, Analysis of the relationship between bare soil evaporation and soil moisture simulated by 13 land surface schemes for a simple non-vegetated site, Global and Planetary Change, 13 (1996) 47-56.

[81] C.M. Carter, H.A. van der Sloot, D. Cooling, A. van Zomeren, T. Matheson, Characterization of untreated and neutralized bauxite residue for improved waste management, Environmental Engineering Science, 25 (2008) 475-488.

[82] B.I. Whittington, Quantification and characterisation of hydrogarnet and cancrinite present in desilication product by powder X-ray diffraction, 4th International Alumina Quality Workshop, (1996) 413-422.

[83] B.I. Whittington, The chemistry of $\mathrm{CaO}$ and $\mathrm{Ca}(\mathrm{OH})_{2}$ relating to the Bayer process, Hydrometallurgy, 43 (1996) 13-35.

[84] K.W. Perrott, Surface charge characteristics of amorphous aluminosilicates, Clays and Clay Minerals, 25 (1977) 417-421.

[85] D.A. Dzombak, F.M.M. Morel, Surface Complexation Modeling : Hydrous Ferric Oxide, Wiley, New York, 1990.

[86] Y. Watanabe, H. Yamada, J. Tanaka, Y. Komatsu, Y. Moriyoshi, Ammonium ion exchange of synthetic zeolites: The effect of their open-window sizes, pore structures, and cation exchange capacities, Separation Science and Technology, 39 (2004) 20912104.

[87] R.M. Barrer, Klinowsk.J, H.S. Sherry, Zeolite exchangers - Thermodynamic treatment when not all ions are exchangeable, Journal of the Chemical SocietyFaraday Transactions, 69 (1973) 1669-1676.

[88] R.M. Barrer, R.P. Townsend, Ion-exchange equilibria in zeolites and clay-minerals Different concentration scales and derived thermodynamic functions, Journal of the Chemical Society-Faraday Transactions, 80 (1984) 629-640.

[89] C. Colella, Ion exchange equilibria in zeolite minerals, Mineralium Deposita, 31 (1996) 554-562. 
[90] R.T. Pabalan, F.P. Bertetti, Cation-exchange properties of natural zeolites, in: Natural Zeolites: Occurrence, Properties, Applications, 2001, pp. 453-518.

[91] J.W.C. Wong, G.E. Ho, Cation exchange behavior of bauxite refining residues from Western Australia, Journal of Environmental Quality, 24 (1995) 461-466.

[92] J. Anderson, R.W. Bell, I.R. Phillips, Mobility of cations in bauxite residue sand treated with residue fines, in: Joint Australian Society of Soil Science-New Zealand Society of Soil Science Conference, Massey, New Zealand, 2008.

[93] N.W. Menzies, I.M. Fulton, W.J. Morrell, Seawater neutralization of alkaline bauxite residue and implications for revegetation, Journal of Environmental Quality, 33 (2004) 1877-1884.

[94] C. Hanahan, D. McConchie, J. Pohl, R. Creelman, M. Clark, C. Stocksiek, Chemistry of seawater neutralization of bauxite refinery residues (red mud), Environmental Engineering Science, 21 (2004) 125-138.

[95] J. Eastham, T. Morald, P. Aylmore, Effective nutrient sources for plant growth on bauxite residue: I. Comparing organic and inorganic fertilizers, Water, Air, and Soil Pollution, 176 (2006) 5-19.

[96] R.D. Fuller, E.D.P. Nelson, C.J. Richardson, Reclamation of Red Mud (Bauxite Residues) using alkaline-tolerant grasses with organic amendments, Journal of Environmental Quality, 11 (1982) 533-539.

[97] J.W.C. Wong, G. Ho, Sewage-sludge as organic ameliorant for revegetation of fine bauxite refining residue, Resources, Conservation and Recycling, 11 (1994) 297-309.

[98] J. Eastham, T. Morald, Effective nutrient sources for plant growth on bauxite residue: II. Evaluating the response to inorganic fertilizers, Water, Air, and Soil Pollution, 171 (2006) 315-331.

[99] J.C. van Dam, R.A. Feddes, Numerical simulation of infiltration, evaporation and shallow groundwater levels with the Richards equation, J Hydrol, 233 (2000) 72-85.

[100] E.G. Lappala, R.W. Healy, E.P. Weeks, 1987. Documentation of computer program VS2D to solve the equations of fluid flow in variably saturated porous media. U.S. Geological Surfay: Denver, Colorado.

[101] COMSOL Multiphysics ${ }^{\circledR}, 2008$. Pesticide transport and reaction in soil, Earth Science Module Model Library.

[102] I. Kosztin, B. Barz, L. Janosi, Calculating potentials of mean force and diffusion coefficients from nonequilibrium processes without Jarzynski's equality, Journal of Chemical Physics, 124 (2006) -.

[103] J. Li, M. Hesse, J. Ziegler, A.W. Woods, An arbitrary Lagrangian Eulerian method for moving-boundary problems and its application to jumping over water, Journal of Computational Physics, 208 (2005) 289-314.

[104] H.J. Vogel, O. Ippisch, Estimation of a critical spatial discretization limit for solving Richards' equation at large scales, Vadose Zone Journal, 7 (2008) 112-114. 
1031

1032

1033

1034

1035

1036

1037

1038

1039

1040

1041

1042

1043

1044

1045

1046

1047

1048

1049

1050

1051

1052
[105] Wolfram MathWorld, 2011. Heaviside step function, Available from: http://mathworld.wolfram.com/HeavisideStepFunction.html, accessed 15.04.2011.

\section{Appendix A: Sequential Solution of Flow and Transport}

Using the coupling of COMSOL and IPhreeqc, the simultaneous solution of the non-linear partial differential equation of variably saturated flow together with numerous transport equations for multi-component solutions in complex domains quickly becomes unstable with excessive memory requirements. In order to increase the efficiency and stability of COMSOL computations, flow and transport were solved sequentially using COMSOL's segregated solver. This assumes a strict one-way coupling between the two processes. Thus, the iterative solution of Richards' equation is only computed for the pressure variable. The resulting timedependent flow field is then input into the multi-component solute transport equations, which are linear and thus easier and faster to solve.

\section{Appendix B: Parallelization}

During reaction calculations in IPhreeqc, each node of the discretized simulation domain is represented by an independent geochemical batch system. Thus, large domains require the computation of several thousands of batch systems, which may lead to long computation times particularly if complex kinetic reactions are involved. For increased computational efficiency, reaction calculations were parallelized, making use of MATLAB's single program multiple data algorithm. In this procedure, an IPhreeqc COM-object is initialized on each of the engaged processors and the number of batch systems for evaluation is distributed evenly. 
1053 The speed increase that results from distributed reaction calculations scales well with the

1054 number of available processors.

\section{Appendix C: Implementation of Atmospheric and Seepage Face Boundaries}

1056 The interface for Richards' equation in COMSOL's Earth Science Module provides

1057 predefined settings for pressure head and flux boundary conditions. In the case of seepage

1058 face and atmospheric boundaries, however, a flux condition may turn locally into a head

1059 condition and vice versa according to a head-based criterion [e.g., 99, 100]. Since the type of

1060 boundary condition cannot be changed during a simulation, the stiff-spring approach, where a

1061 Neumann statement about flux is used to achieve a Dirichlet condition for the pressure head,

1062 has to be employed [101].

1063 A seepage face boundary conceptualizes a porous medium that drains freely and where the

1064 out-flowing water is removed rapidly enough such that it does not build up on the surface.

1065 Consequently, a zero head condition applies as long as there is potential outflow from the

1066 domain (the pressure head within the domain is greater than zero). In unsaturated conditions

1067 (negative pressure head), the boundary turns into a no-flow boundary. The stiff-spring

1068 representation of a seepage face boundary is given by

$q_{0}=\left\{\begin{array}{rr}0, & H_{0} \leq 0 \\ -k_{s p} H_{0}, & H_{0}>0\end{array}\right.$

1069 where $q_{0}\left(\mathrm{~m} \mathrm{~s}^{-1}\right)$ is the inward flux crossing the boundary, $H_{0}(\mathrm{~m})$ is the actual pressure head

1070 at the boundary and $k_{s p}\left(\mathrm{~s}^{-1}\right)$ is the positive spring constant. The flux $-k_{s p} H_{0}$ must be of a

1071 magnitude sufficient to prevent build-up of water and fix the pressure head at the boundary

1072 effectively to zero. Therefore, the accuracy of the stiff-spring representation increases with

1073 the magnitude of $k_{s p}$, however at the cost of numerical efficiency and stability $[102,103]$. 
1074 Atmospheric boundary conditions are governed by the recharge flux $r(t)\left(\mathrm{m} \mathrm{s}^{-1}\right)$, which is the 1075 difference between the absolute values of rainfall and potential evaporation. In the case of 1076 bare soil evaporation, $r(t)$ is limited by the water availability in the soil. Once a critical 1077 negative pressure head, $H_{\text {crit }}(\mathrm{m})$, at the soil surface is reached, the boundary conceptually 1078 switches from a specified flux boundary to a head condition. $H_{\text {crit }}$ is the pressure potential of 1079 the atmosphere and a measure of the atmospheric evaporation demand [100]. In dry and hot 1080 weather situations, it may exceed in magnitude $-10^{3} \mathrm{~m}$. Thus, in contrast to the seepage face 1081 boundary, the change between constant head and specified flux occurs in the dry range of the 1082 moisture spectrum, where $H_{0}$ is extremely sensitive to the applied flux. In order to avoid oscillations of the numerical scheme a smooth spring function is required that merges seamlessly with the flux in unconstrained conditions. For the representation of evaporation 1085 boundaries, we therefore make use of the following condition:

$q_{0}=-r(t) \tanh \left[\frac{\xi}{r(t)}\left(H_{0}-H_{c r i t}\right)\right]$

1086 where $\xi\left(\mathrm{T}^{-1}\right)$ is the derivative of $q_{0}$ with respect to $H$ at $H_{\text {crit }}$, which determines implicitly

1087 the width of the transition zone between unconstrained and limited evaporation.

Fig. 17: Boundary flux during negative recharge in the vicinity of the critical pressure head $H_{a}$.

1089 The behaviour of $q_{0}$ in the vicinity of $H_{c r i t}$ is illustrated in Fig. 17. As $H_{0}$ approaches $H_{c r i t}$,

1090 the magnitude of the evaporation flux is reduced continuously until evaporation stops

1091 completely and even gives positive values (condensation) if $H_{\text {crit }}$ is surpassed. This

1092 behaviour is consistent with the physical process, where evaporation from dry soils is

1093 gradually reduced due to limited water availability. Low values of $H_{\text {crit }}$ require a larger

1094 smoothing zone (lower $\xi$ ) and very fine domain discretization near the boundary [104] in order to achieve numerical convergence. 
In the case of positive recharge the boundary flux is limited by the infiltration capacity at the

1097 maximum surface pressure head $H_{p o}(\mathrm{~m})$, which represents the maximum height of ponded

1098 water [56]. Conceptually, the specified flux condition $q_{0}=r(t)$ turns into a head condition

1099 when $H_{0}$ exceeds $H_{p o}$. This can be expressed as a conventional stiff-spring boundary

1100 according to:

$q_{0}=\left\{\begin{aligned} r(t), & H_{0} \leq H_{p o} \\ r(t)-k_{p o}\left(H_{0}-H_{p o}\right), & H_{0}>H_{p o}\end{aligned}\right.$

1101 where $k_{p o}\left(\mathrm{~s}^{-1}\right)$ is the spring constant. The flux $-k_{p o}\left(H_{0}-H_{p o}\right)$ reduces infiltration until the

1102 ponded boundary head is established.

1103 The full atmospheric boundary condition results from combining the evaporation boundary

1104 Eq. (C.2) with the infiltration boundary Eq. (C.3), yielding:

$q_{0}=\left\{\begin{array}{rl}-r(t) \tanh \left[\frac{\xi}{r(t)}\left(H_{0}-H_{c r i t}\right)\right], & r(t)<0 \\ r(t) \mathcal{H}\left(H_{p o}-H_{0}\right)+\left[r(t)-k_{p o}\left(H_{0}-H_{p o}\right)\right] \mathcal{H}\left(H_{0}-H_{p o}\right), & r(t) \geq 0\end{array}\right.$,

1105 where $\mathcal{H}$ is the Heaviside step function [e.g., 105].

1106 Instead of the tanh-function in Eq. (C.4), COMSOL's smoothed version of the Heaviside

1107 function flc2hs can be used. The inwards recharge flux then becomes

$q_{0}=r(t)\left[-1+2\right.$ flc $\left.2 h s\left(H_{0}-H_{c r i t}, \varrho\right)\right], \quad r(t)<0$.

1108 In Eq. (C.5) the transition zone is explicitly determined by the parameter $\varrho(\mathrm{m})$. However the

1109 slope of $q_{0}$ with respect to $H_{0}$ at $H_{c r i t}$, which is relevant for numerical stability, depends on

$1110 \quad H_{\text {crit }}$ and $q_{0}$ 


\section{Appendix D: Particle Size Distribution, Surface Area}

1112 It is generally accepted that the rate of mineral reactions is proportional to the area of the

1113 reacting surface $[45,52]$. In order to determine the macroscopic surface area a particle-size

1114 analysis was performed on washed residue sand (see Section 2.2 for details on washing

1115 procedure) using laser diffraction particle size analysis (LS 13320 Beckman Coulter). In Fig.

111618 , the relative solid volume against particle diameter is displayed as the mean of four

1117 replicates.

1118 Fig. 18: Particle size distribution of washed residue sand.

1119 With the assumption of spherical particles and a measured solid density of $2.74 \mathrm{~g} \mathrm{~cm}^{-3}$ the

1120 specific surface area of residue sand, as derived from the particle size distribution, amounts to $11210.0264 \mathrm{~m}^{2} \mathrm{~g}^{-1}$. 
(a)

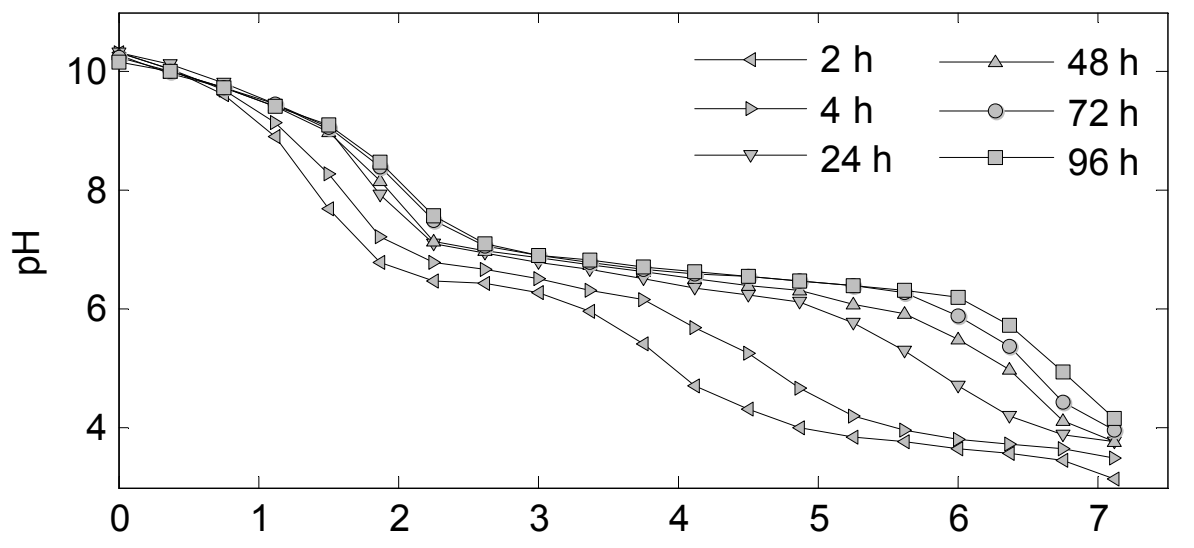

(b)

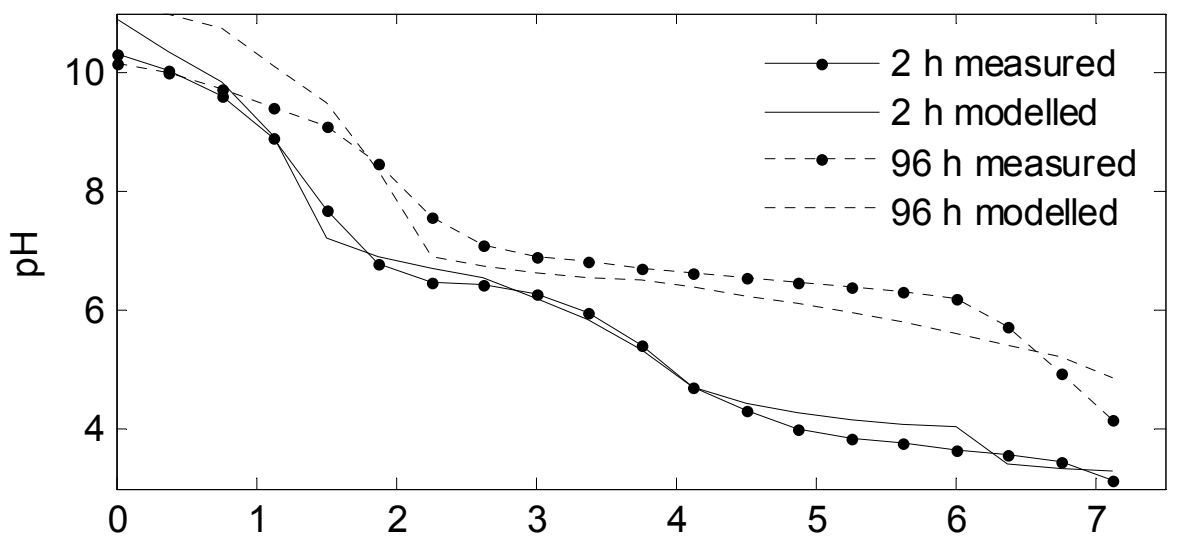

(c)

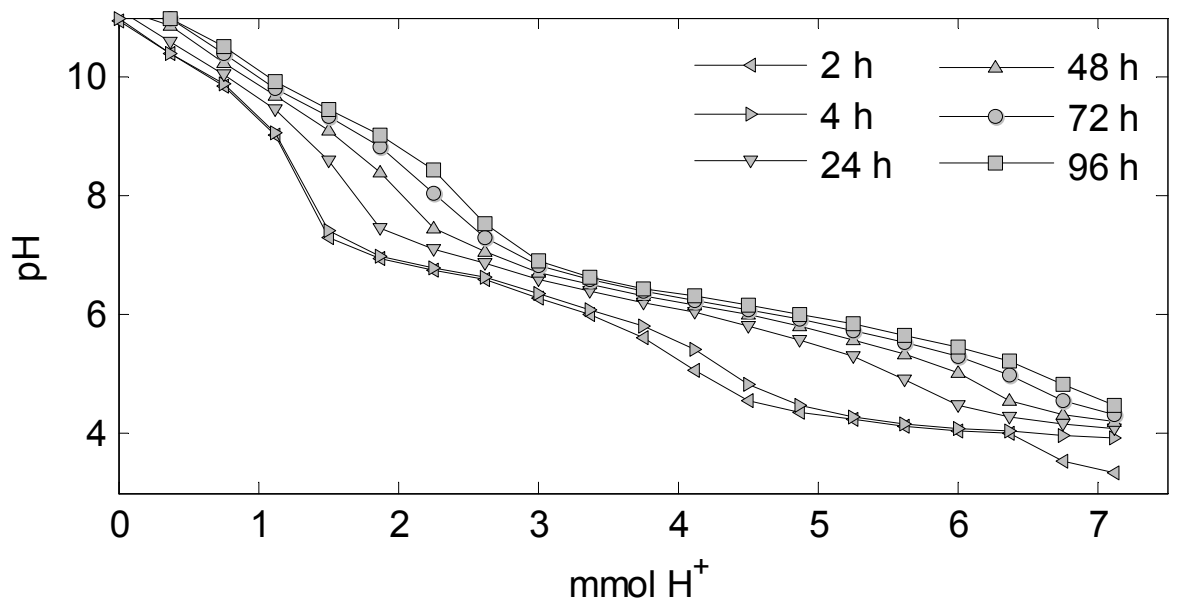

Fig. 1: Measured (a) and simulated acid neutralization curves at thermodynamic equilibrium (b) and including the kinetic dissolution of TCA and sodalite (c). 


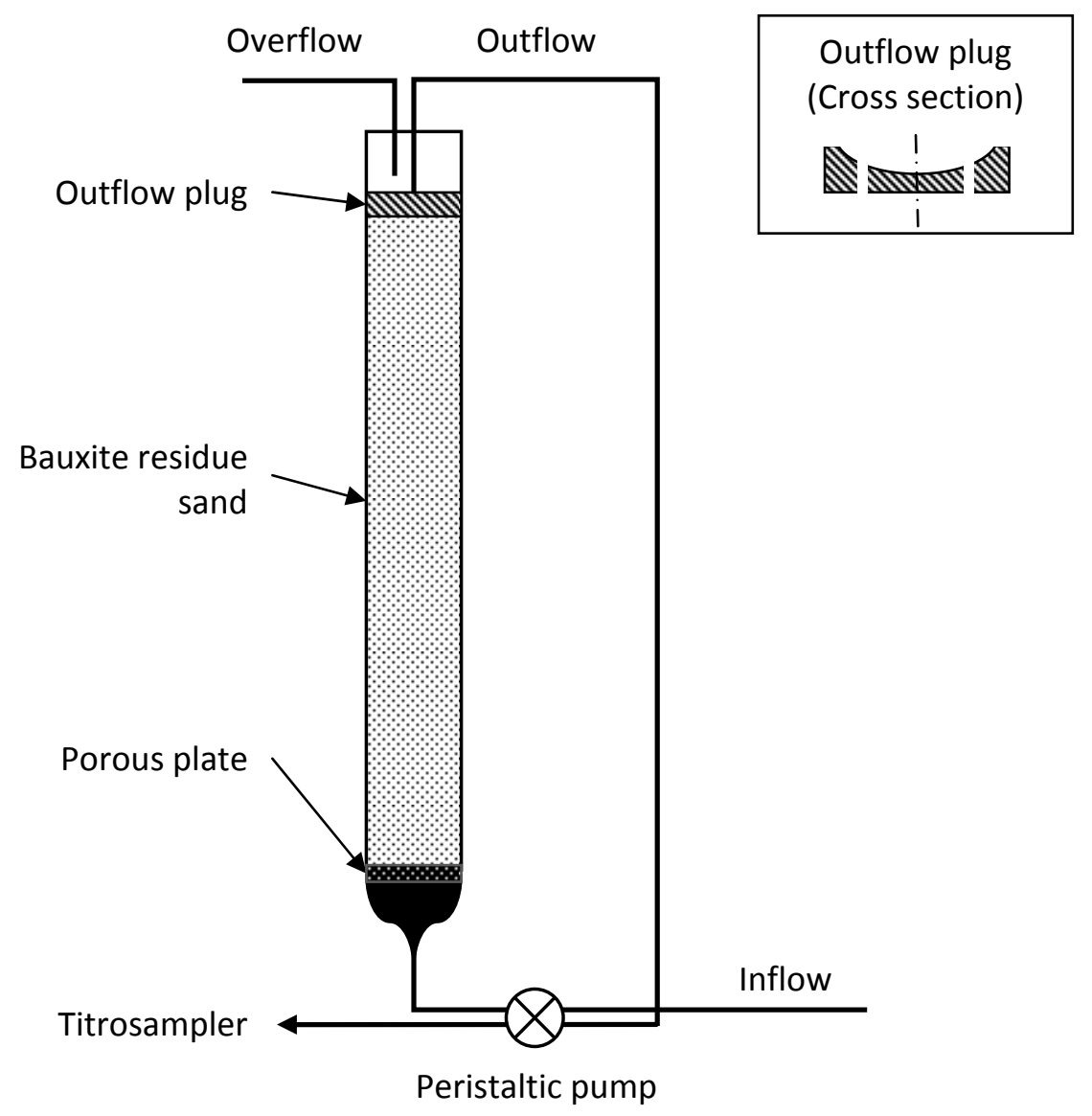

Fig. 2: Upward flow column experiment. 
(a)

(b)
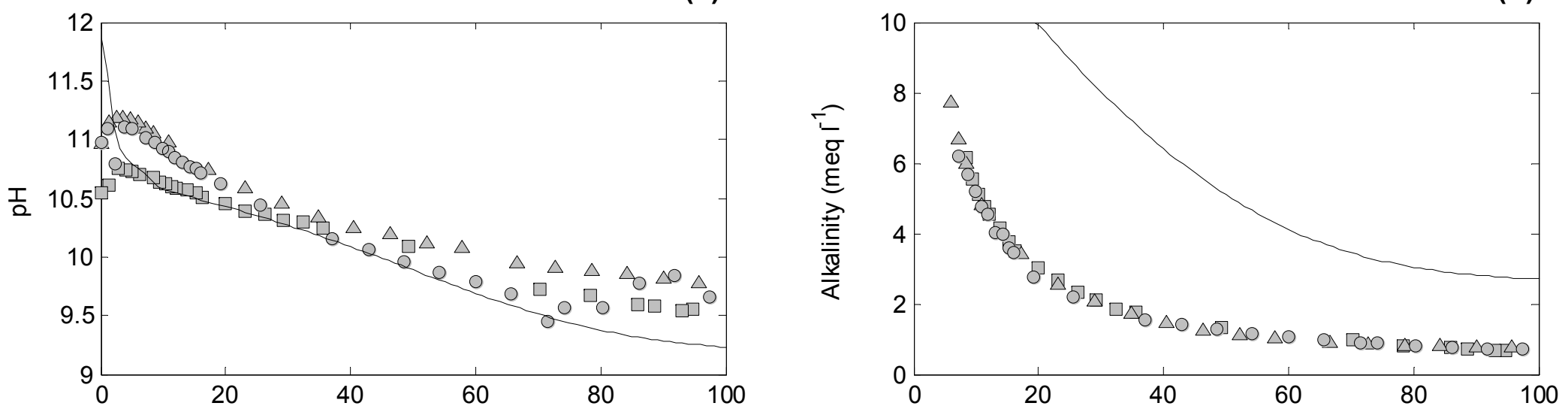

(c)

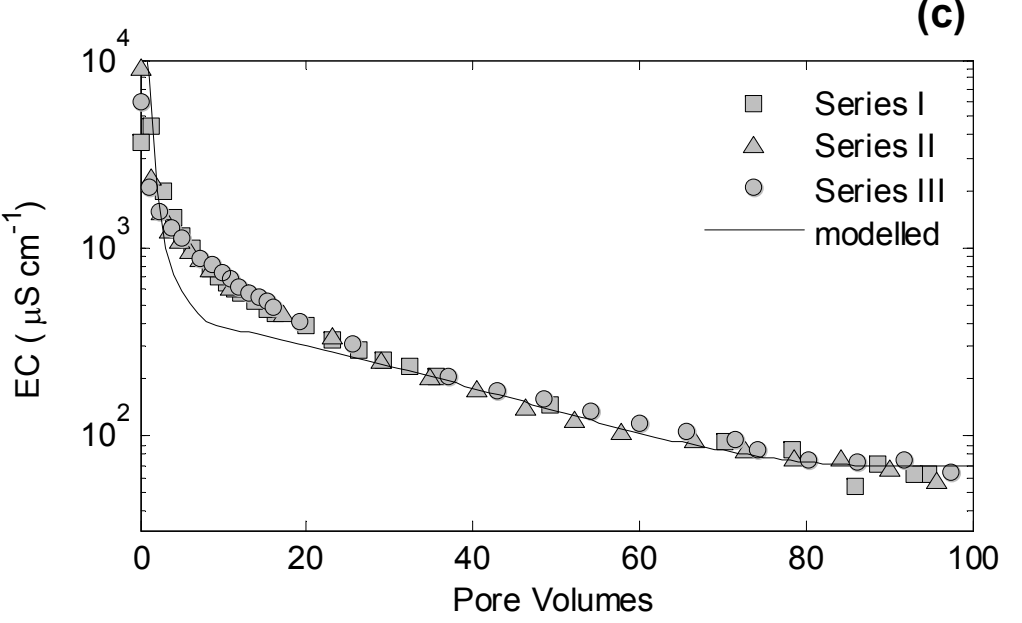

(d)

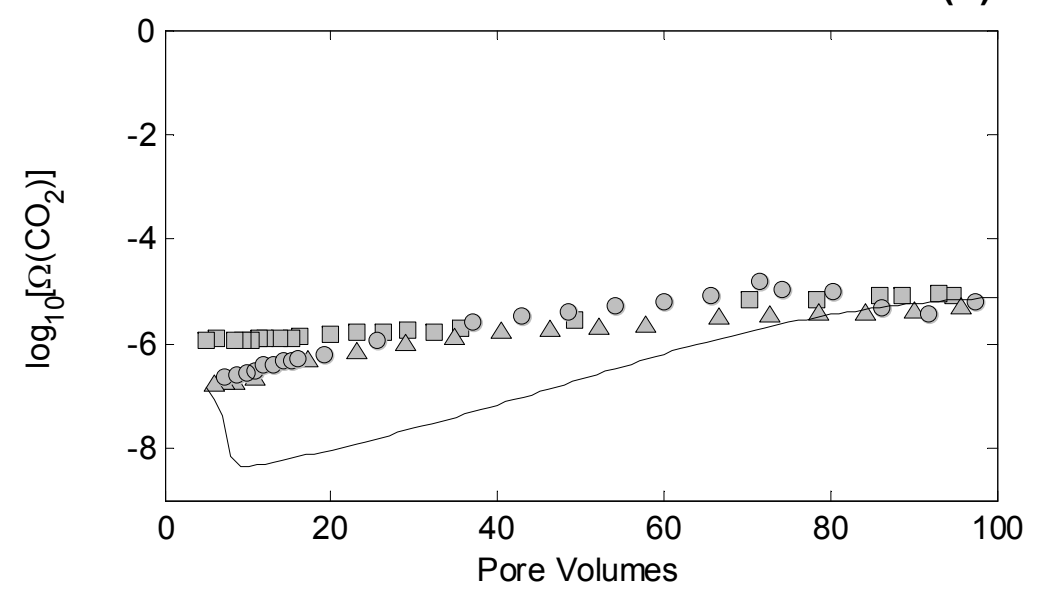

Fig. 3: Results of column experiment for $\mathrm{pH}(\mathrm{a})$, alkalinity (b), electrical conductivity (c) and calculated $\mathrm{CO}_{2}$ saturation (d). 
(a)

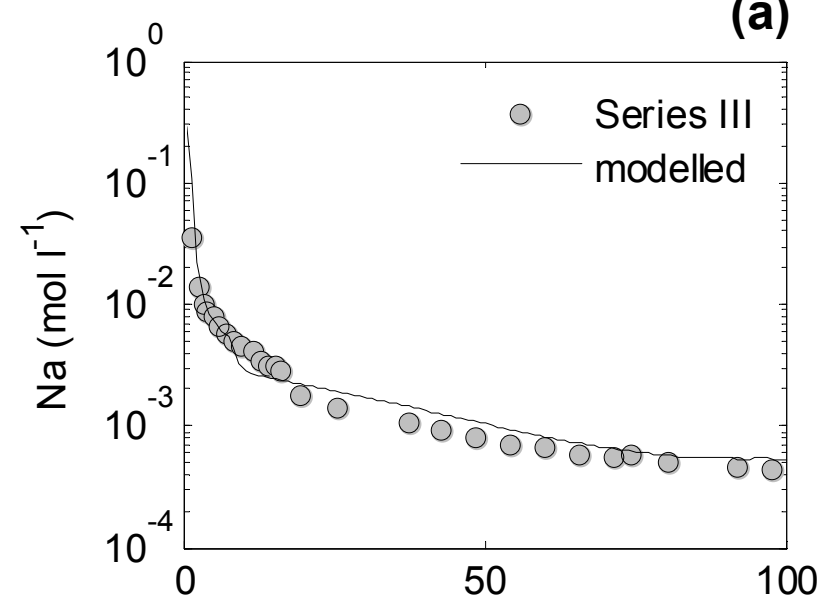

(c)

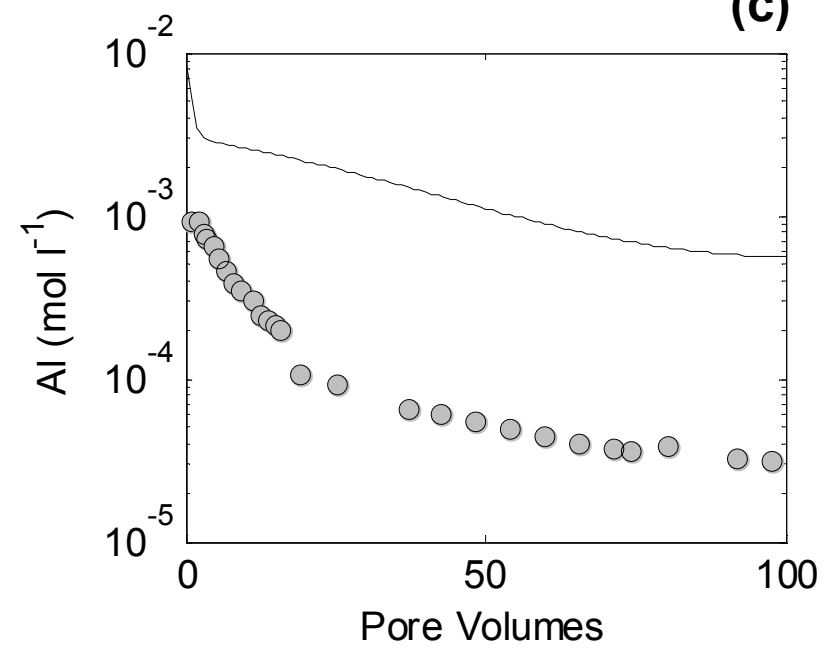

(b)

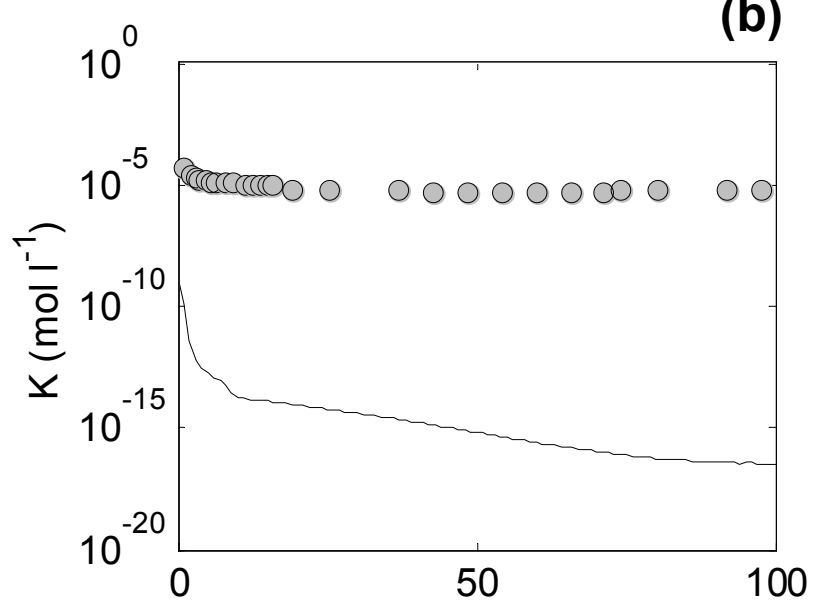

(d)

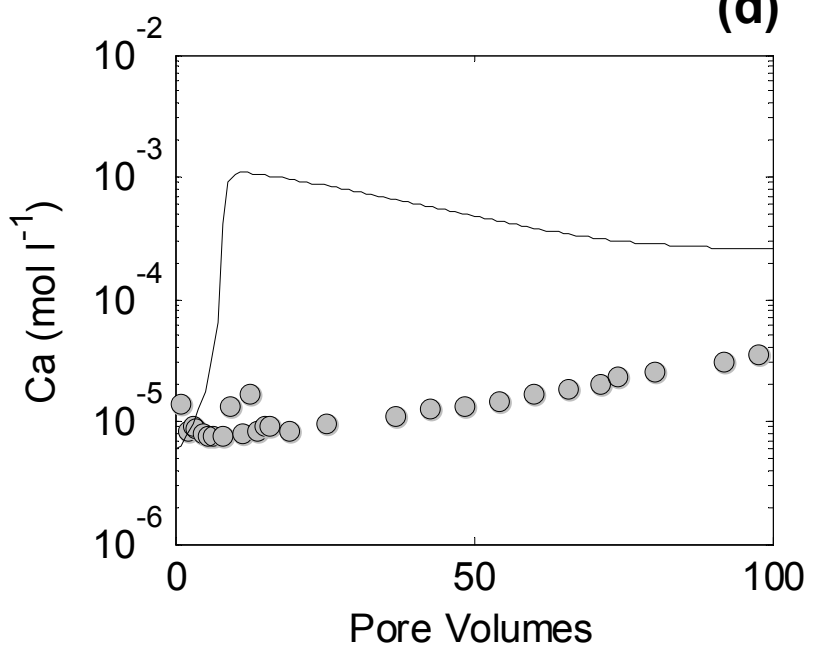

Fig. 4: Element concentrations $\left(\mathrm{mol} \mathrm{I}^{-1}\right.$ ) in the column outflow for (a) $\mathrm{Na}$, (b) K, (c) Al and (d) Ca. 


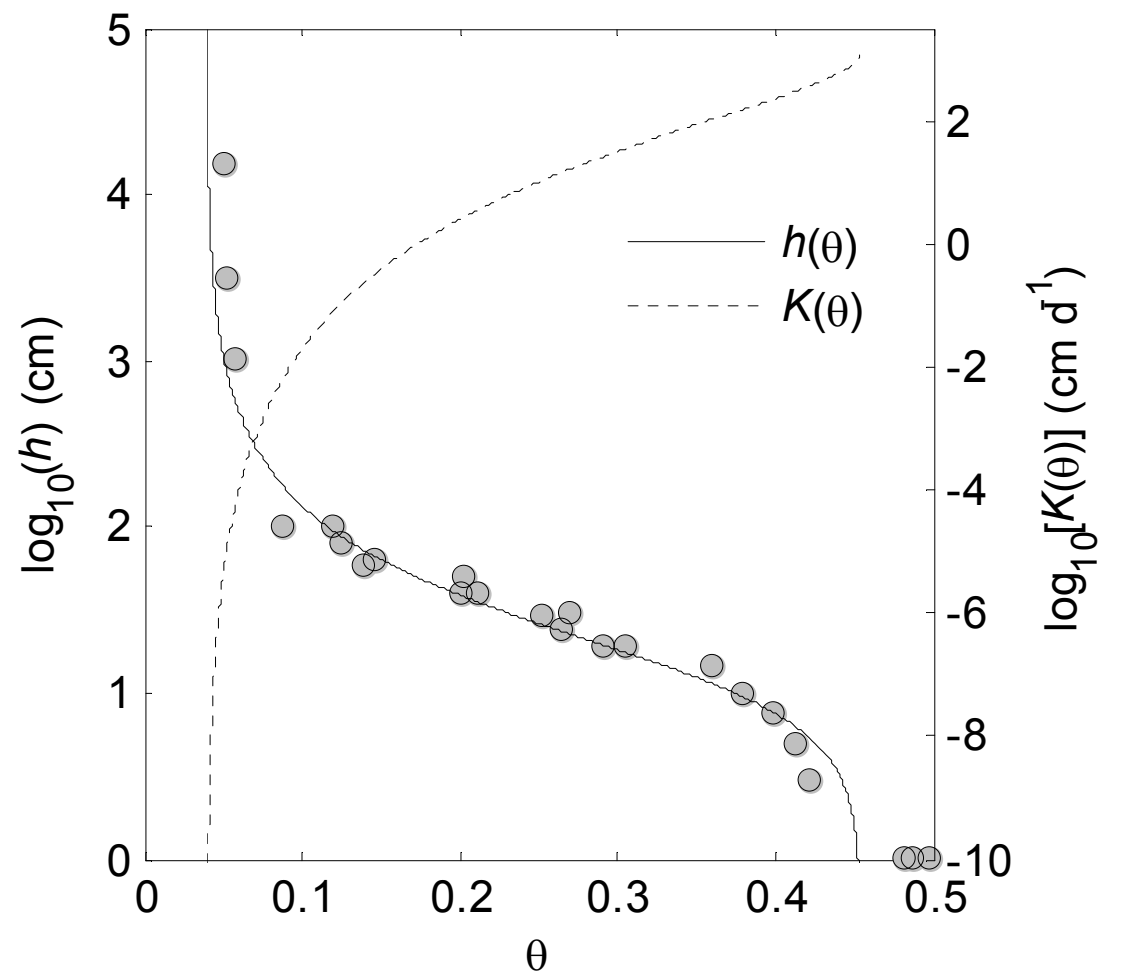

Fig. 5: Water retention and unsaturated hydraulic conductivity of residue sand at the soil surface according to the van Genuchten/Mualem model. 

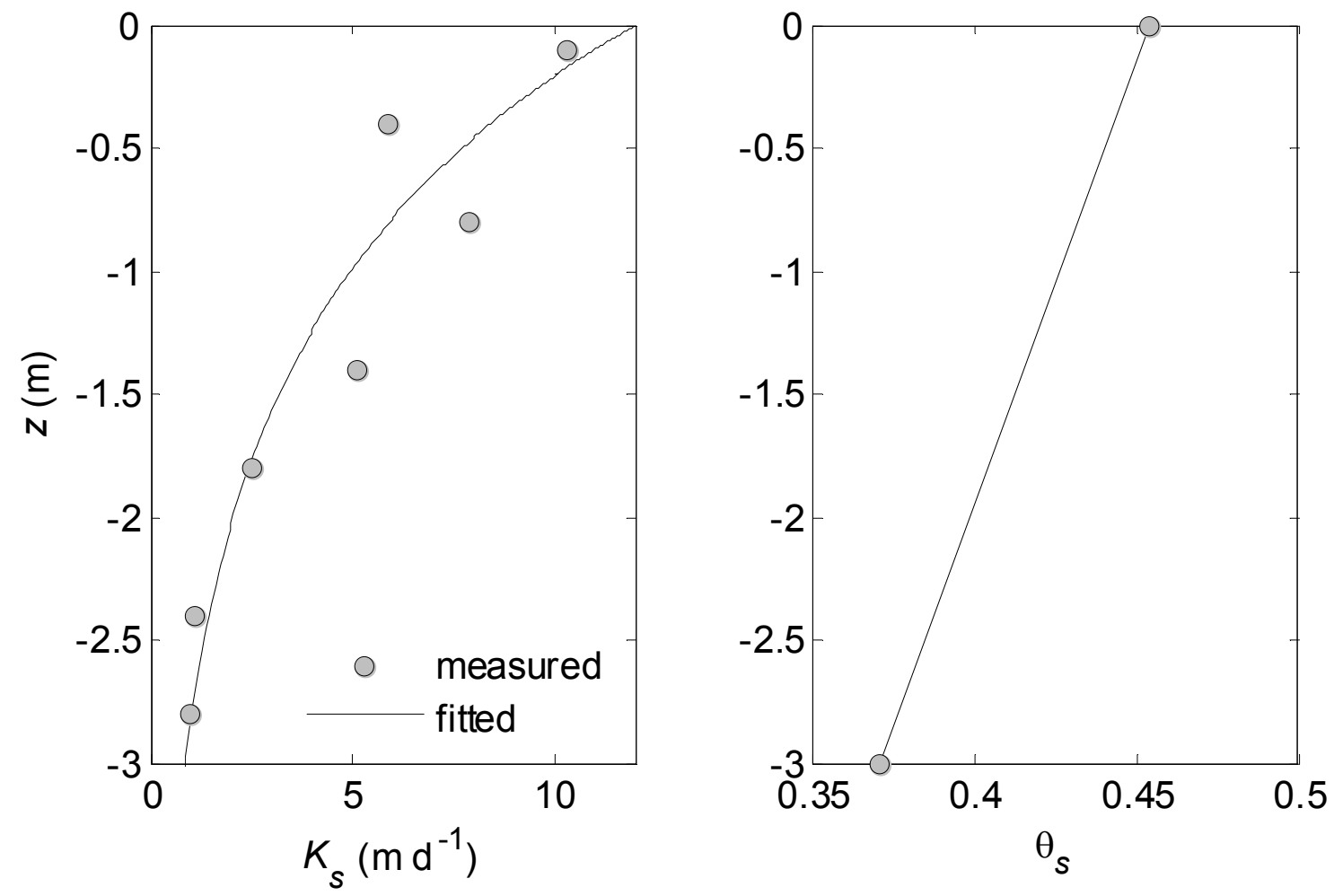

Fig. 6: Depth dependence of saturated hydraulic conductivity $K_{s}$ (left) and saturated water content $\theta_{s}$ (right). 


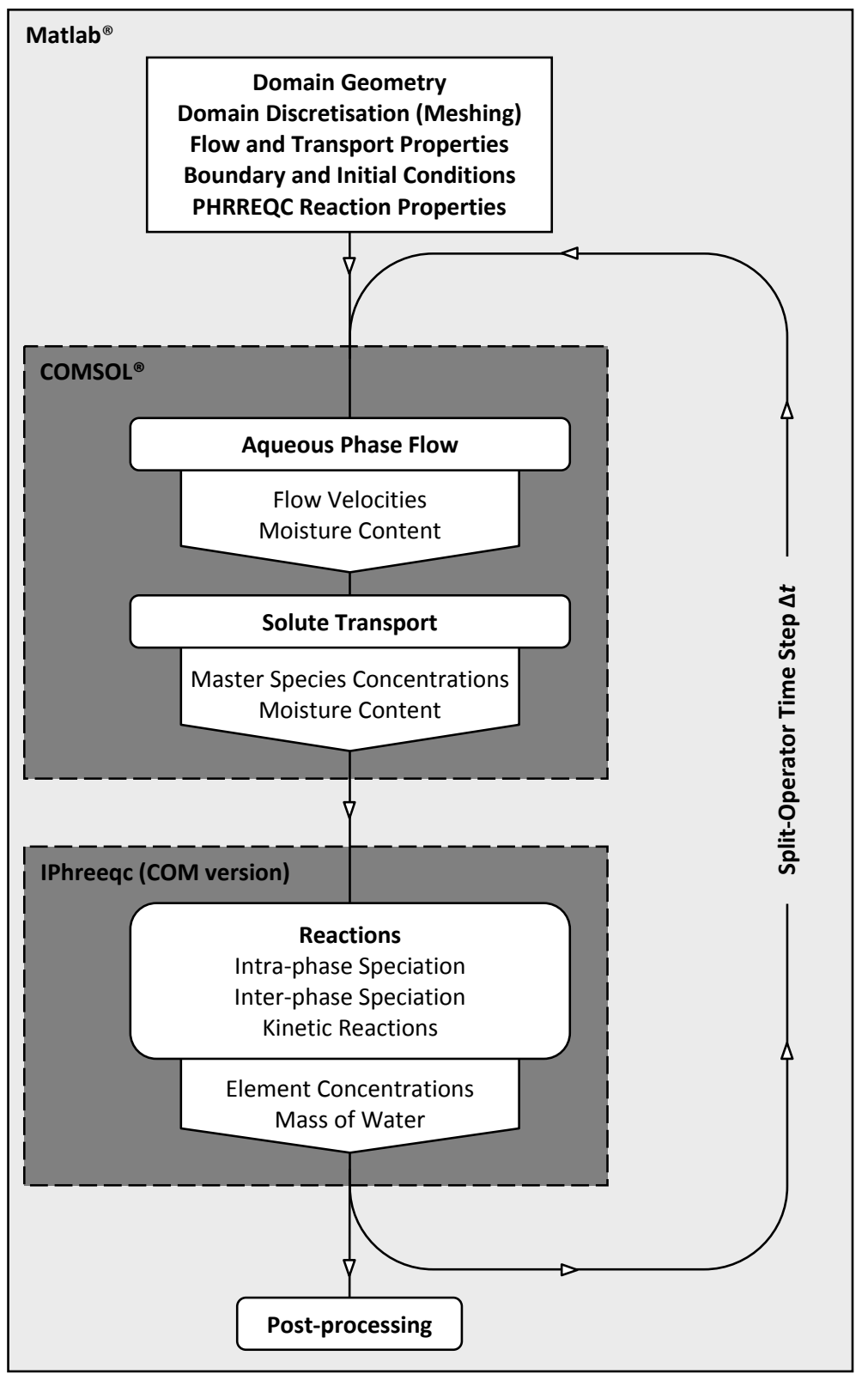

Fig. 7: Program flow and structure. 

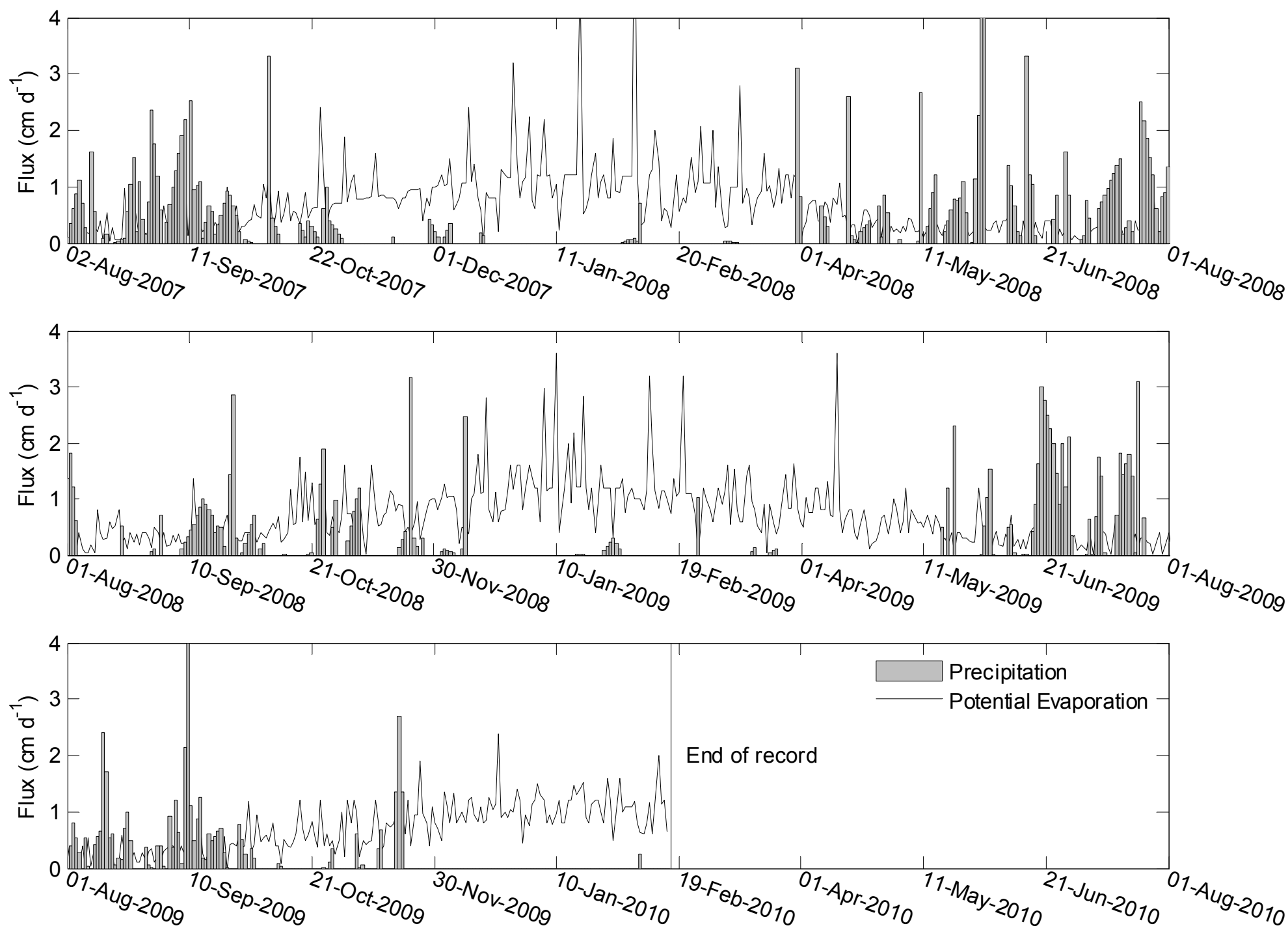

Fig. 8: Time series of rainfall and potential evaporation with reconstructed missing values. 


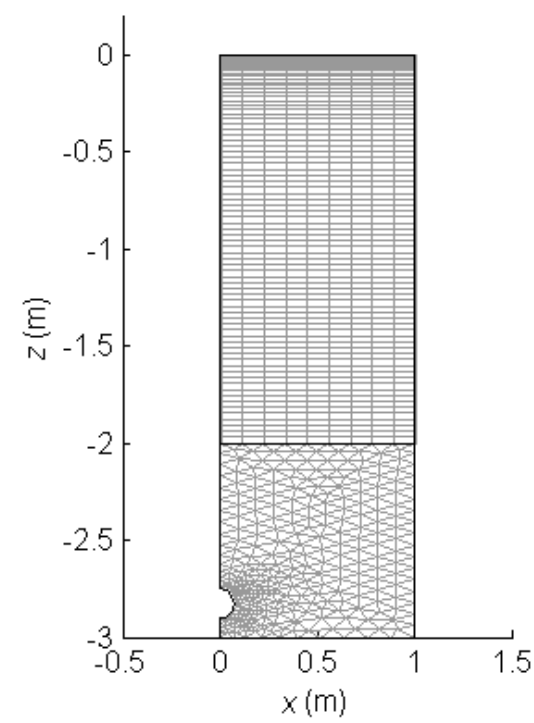

Fig. 9: Lysimeter simulation domain and finite element representation. 


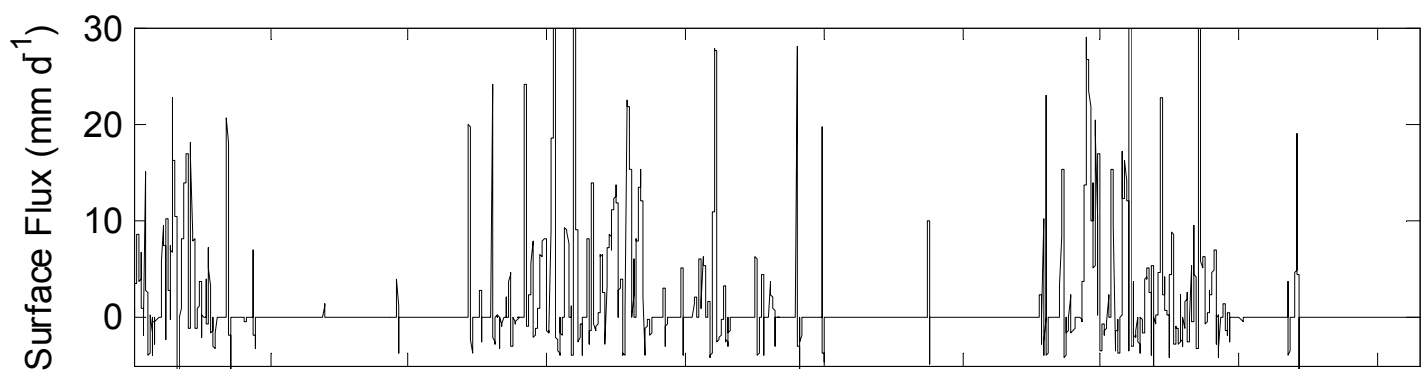

(a)

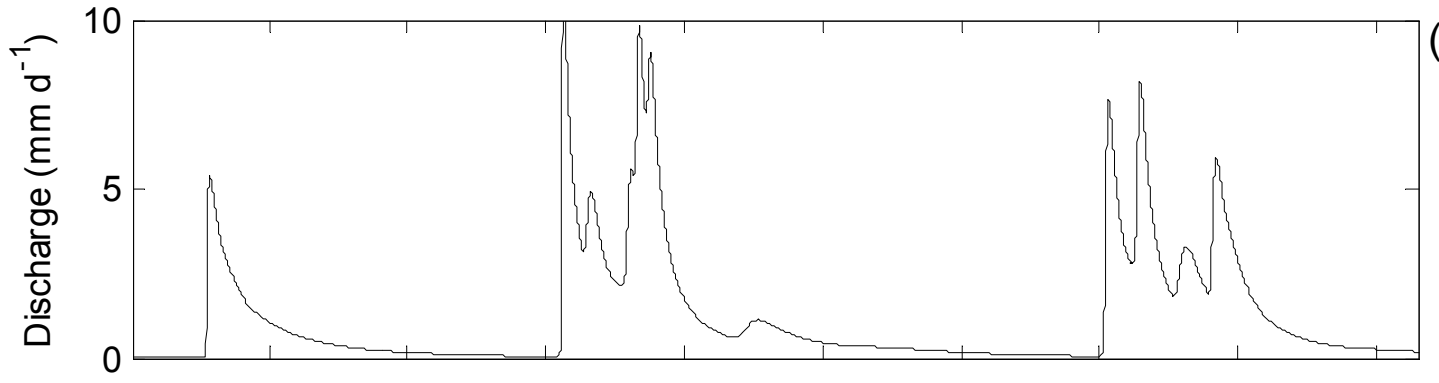

(b)

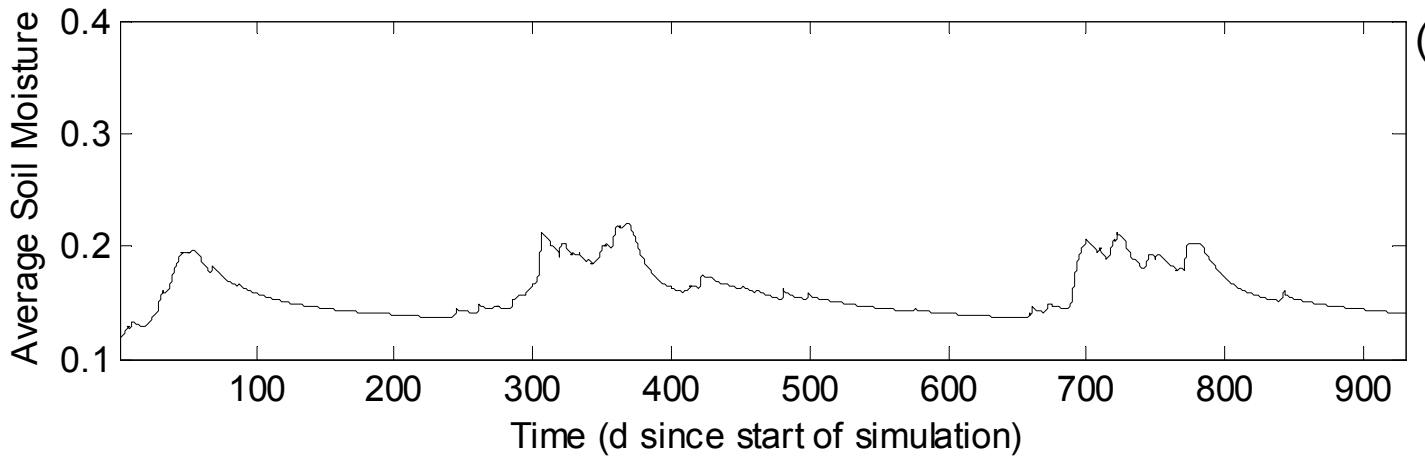

(c)

Fig. 10: Dynamic water balance of lysimeter simulation with (a) surface flux ( $\mathrm{mm} \mathrm{d}^{-1}$ ), (b) drainage at the drainage pipe $\left(\mathrm{mm} \mathrm{d}^{-1}\right)$ and $(\mathrm{c})$ average soil moisture content $\boldsymbol{\theta}$. 

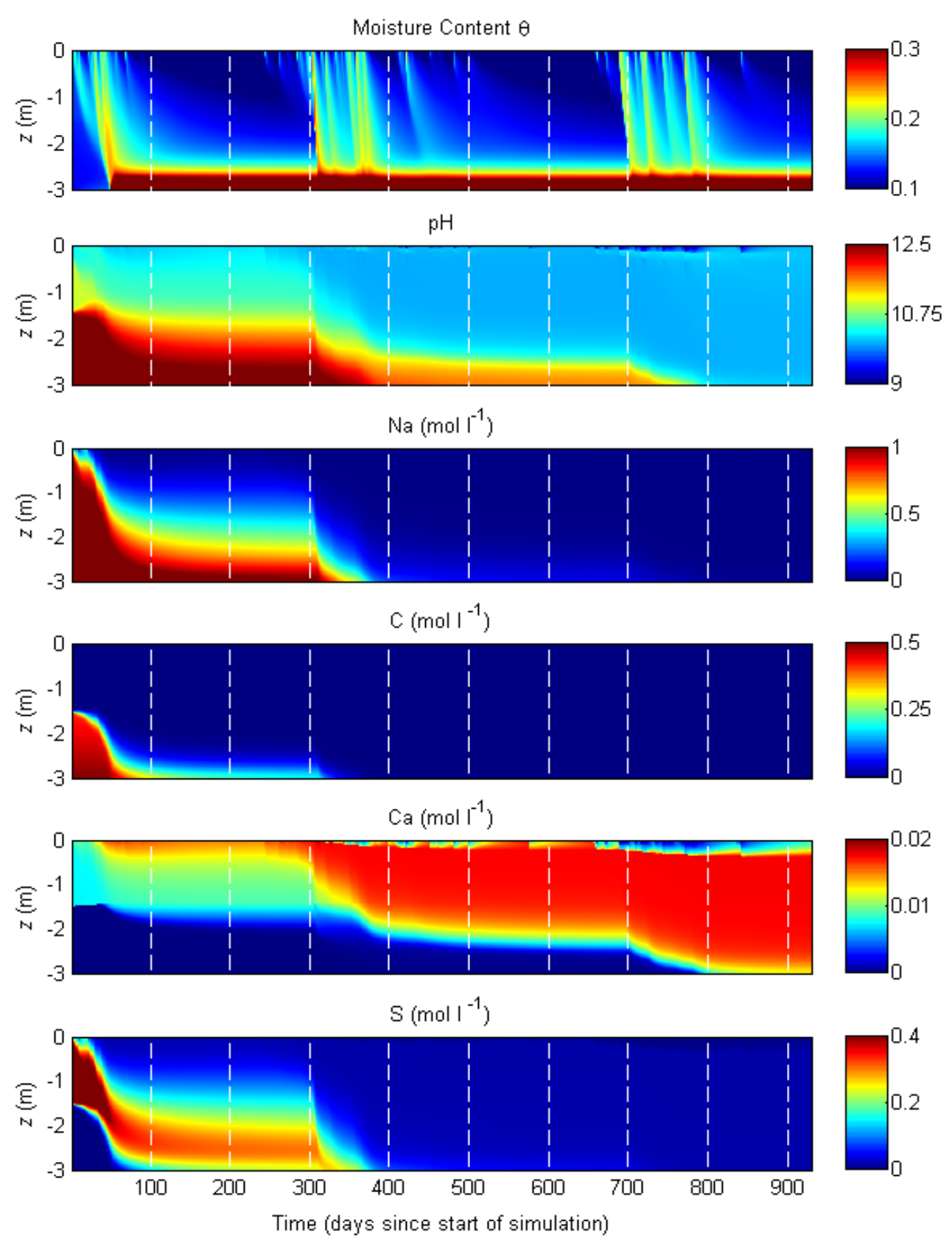
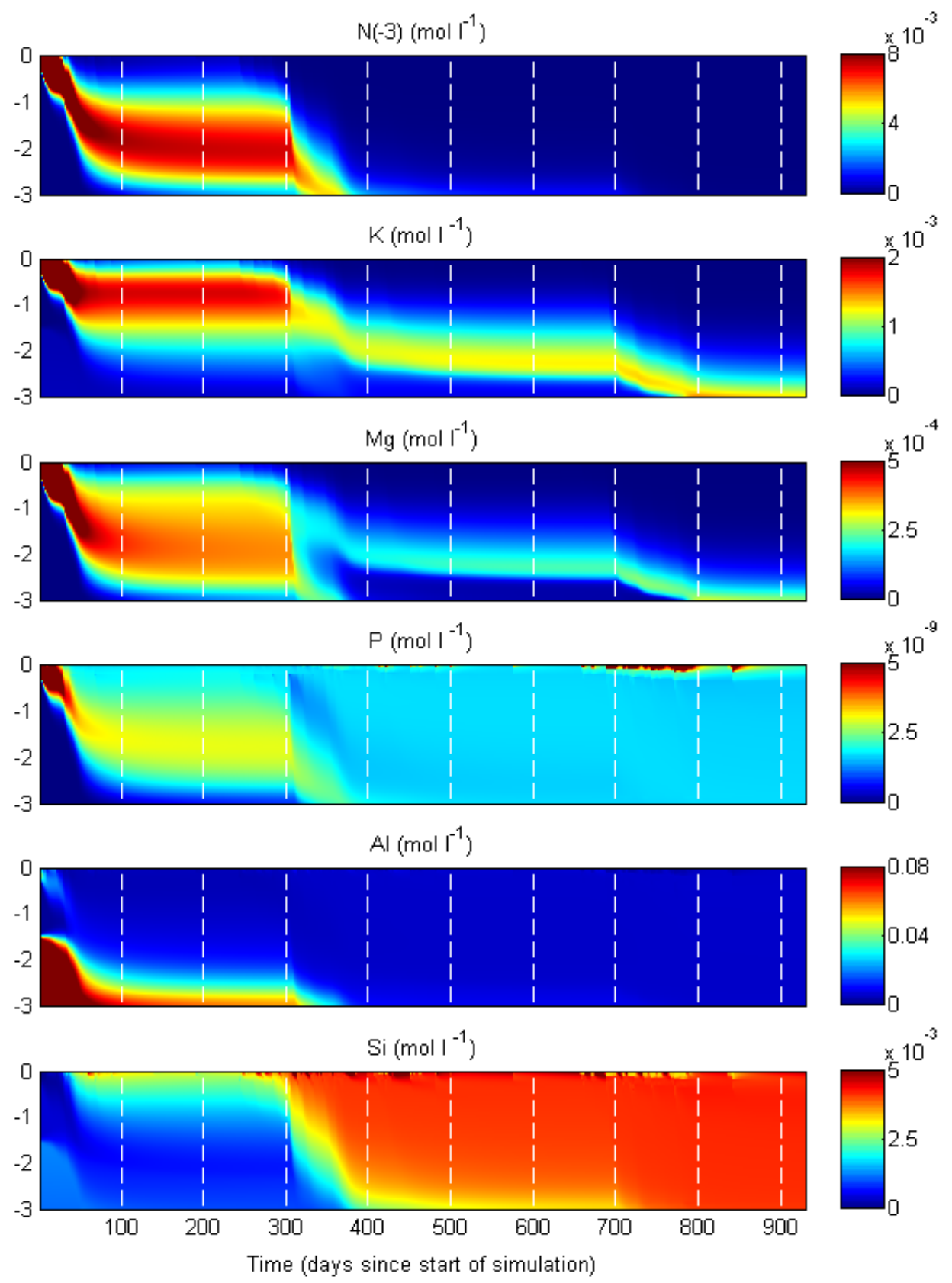

Fig. 11: Evolution of moisture content, $\mathrm{pH}$ and concentration of selected elements at the right domain boundary of the lysimeter simulation. 


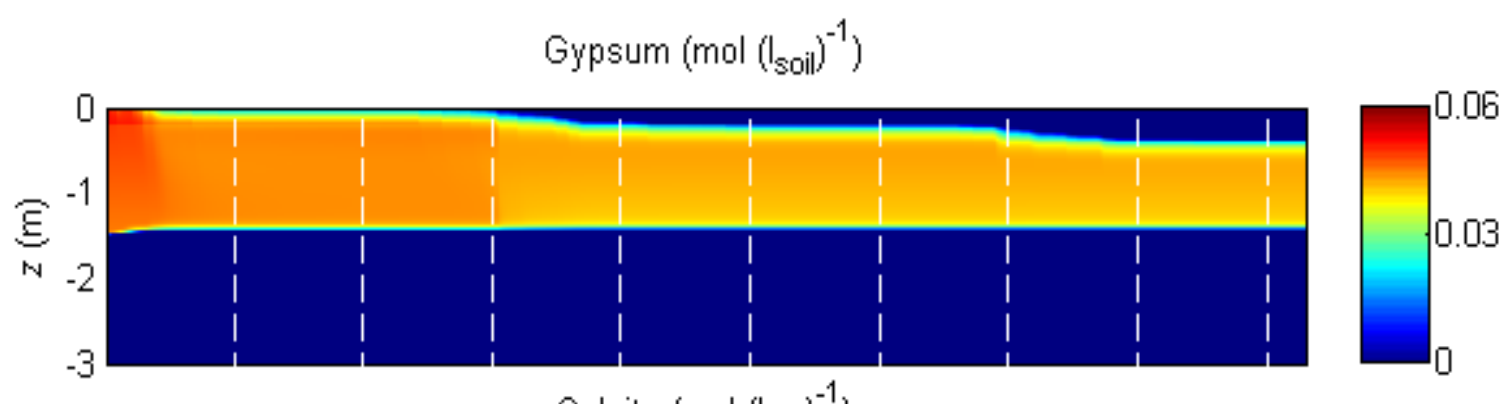

Calcite $\left(\mathrm{mol}_{\left.(\mathrm{soil})^{-1}\right)}\right.$
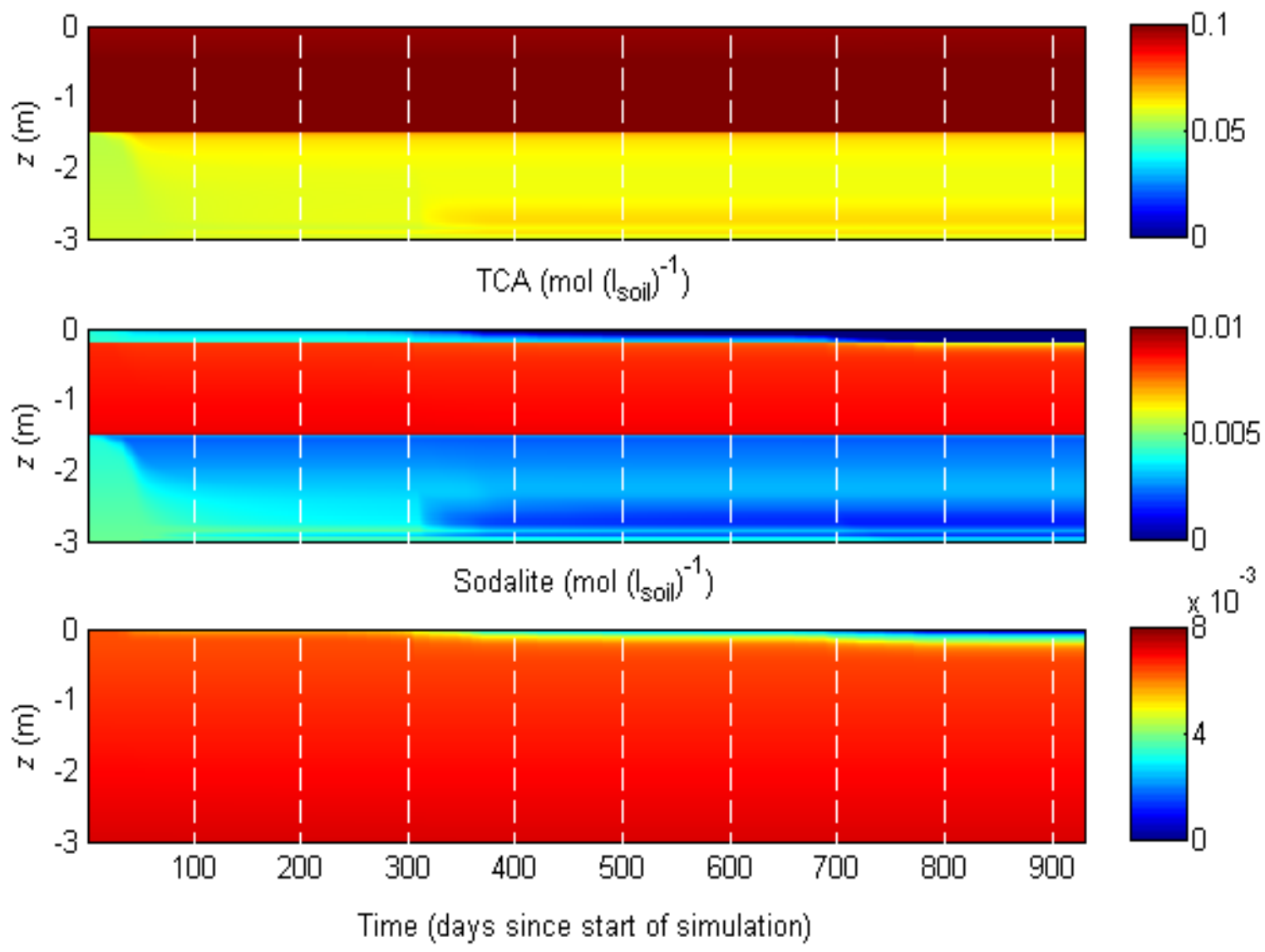

Fig. 12: Evolution of the main minerals at the right domain boundary of the lysimeter simulation. 

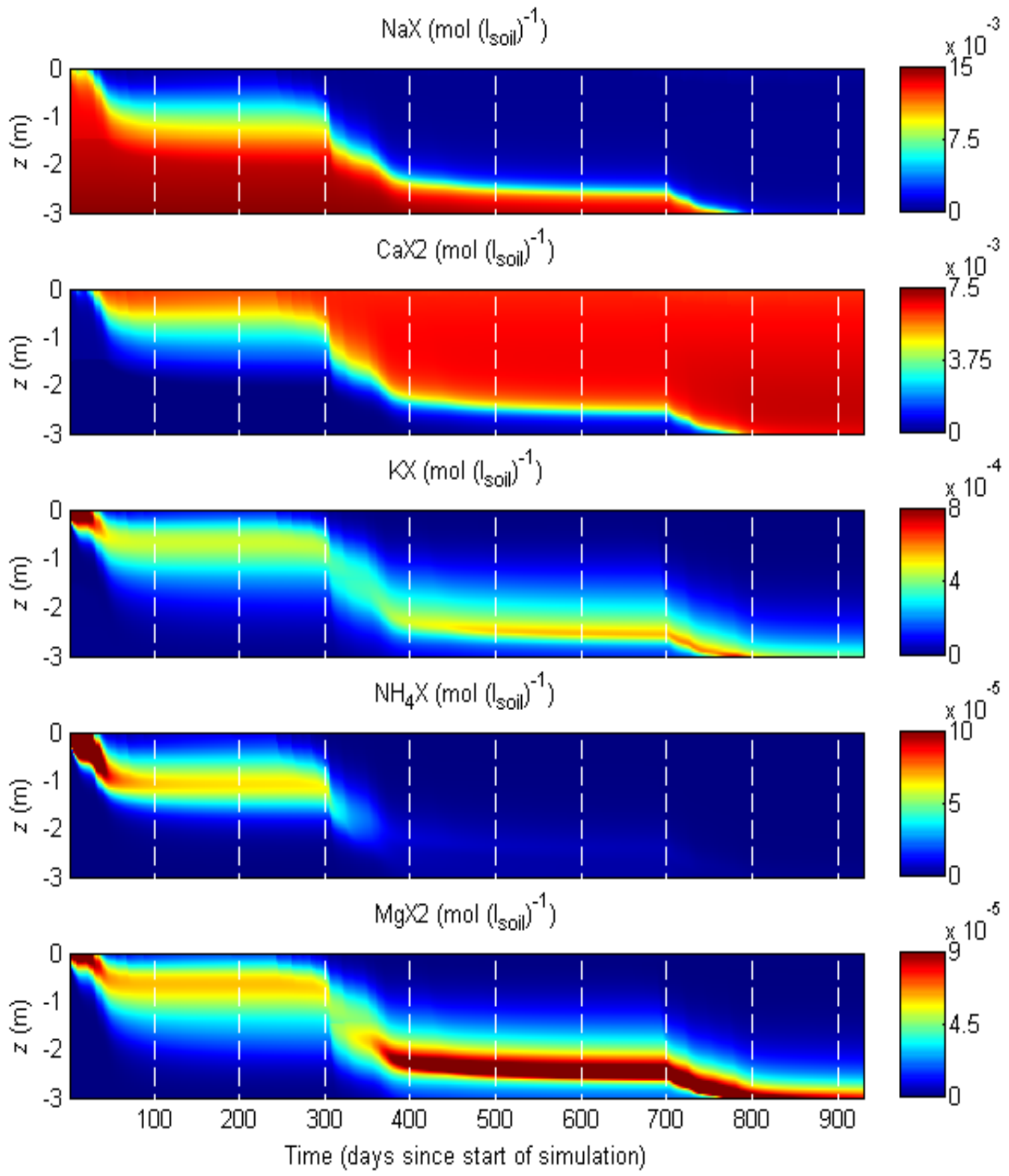

Fig. 13: Evolution of the exchanger composition at the right domain boundary of the lysimeter simulation. 


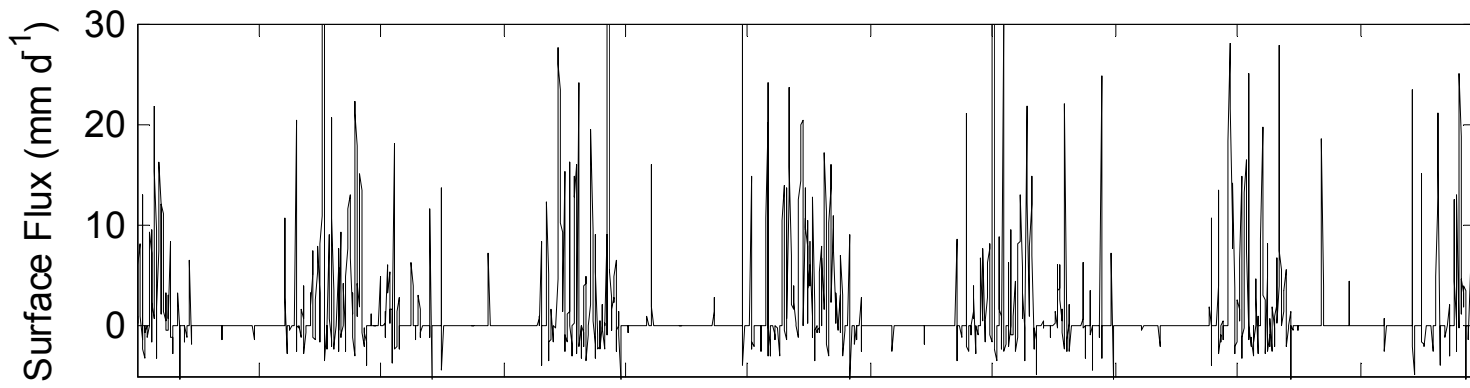

(a)

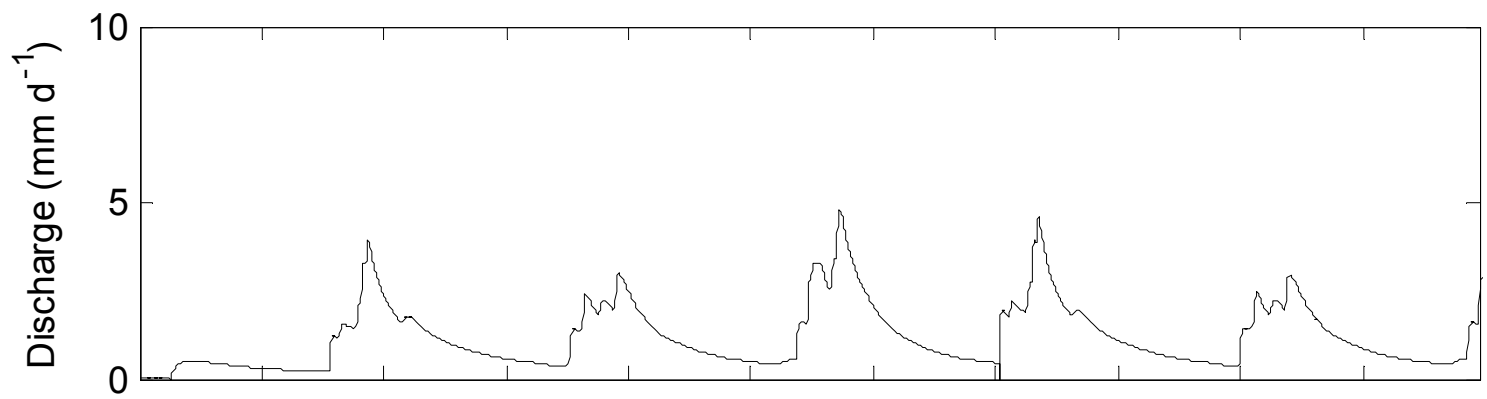

(b)

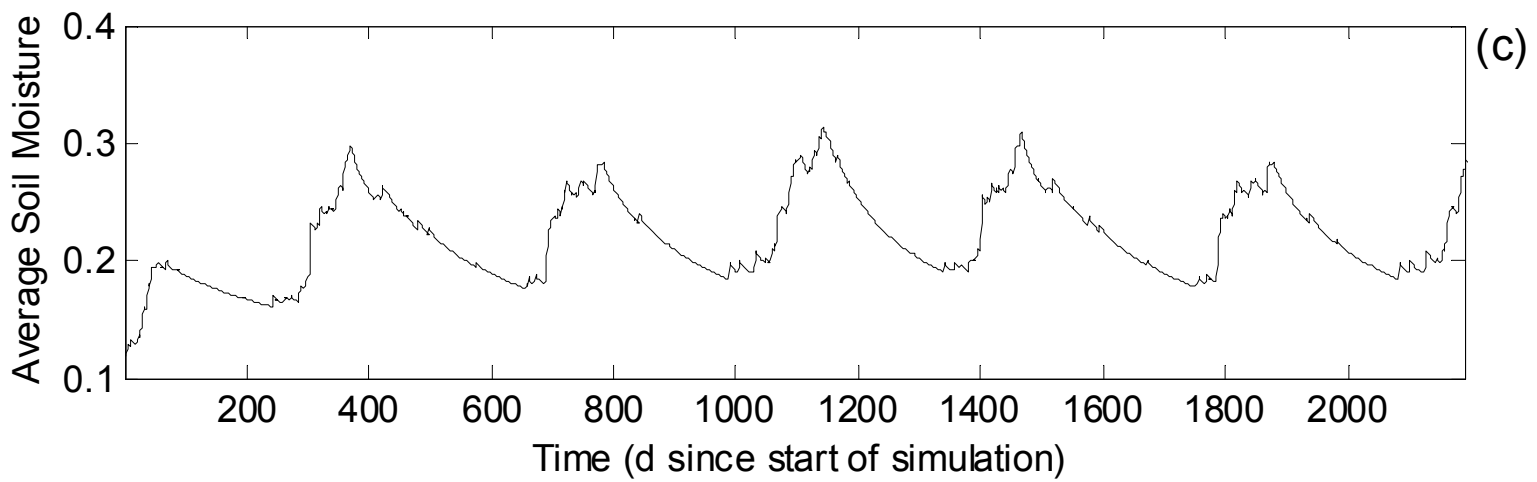

Fig. 14: Dynamic water balance of surface cover simulation, with (a) surface flux ( $\left.\mathrm{mm} \mathrm{d}^{-1}\right)$, (b) drainage (mm $\left.\mathrm{d}^{-1}\right)$ and (c) average soil moisture content $\boldsymbol{\theta}$. 


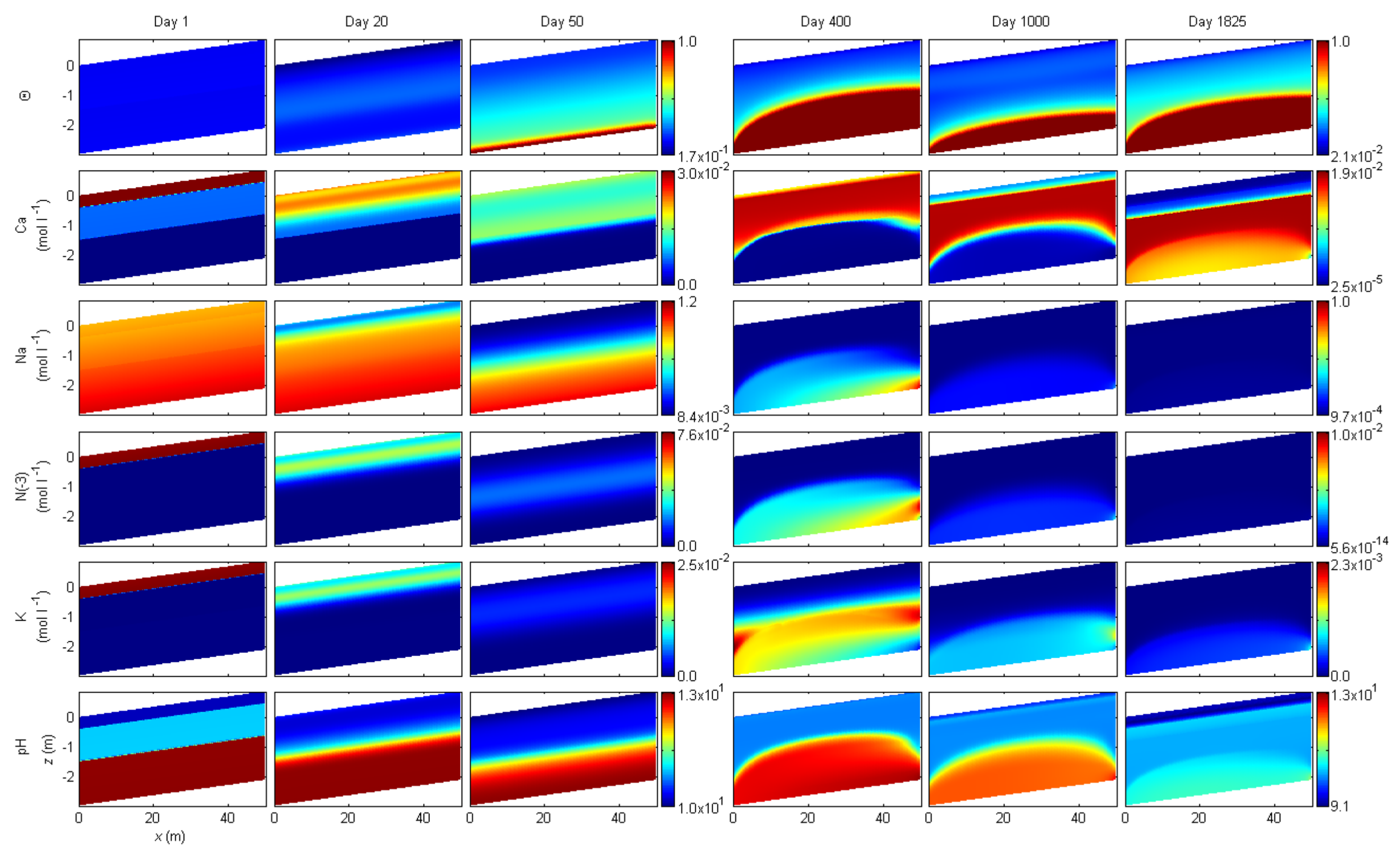

Fig. 15: Evolution of normalized moisture content, concentrations of selected elements and pH profiles of the surface cover simulation at $1,20,50,400,600$ and $1825 \mathrm{~d}$. 


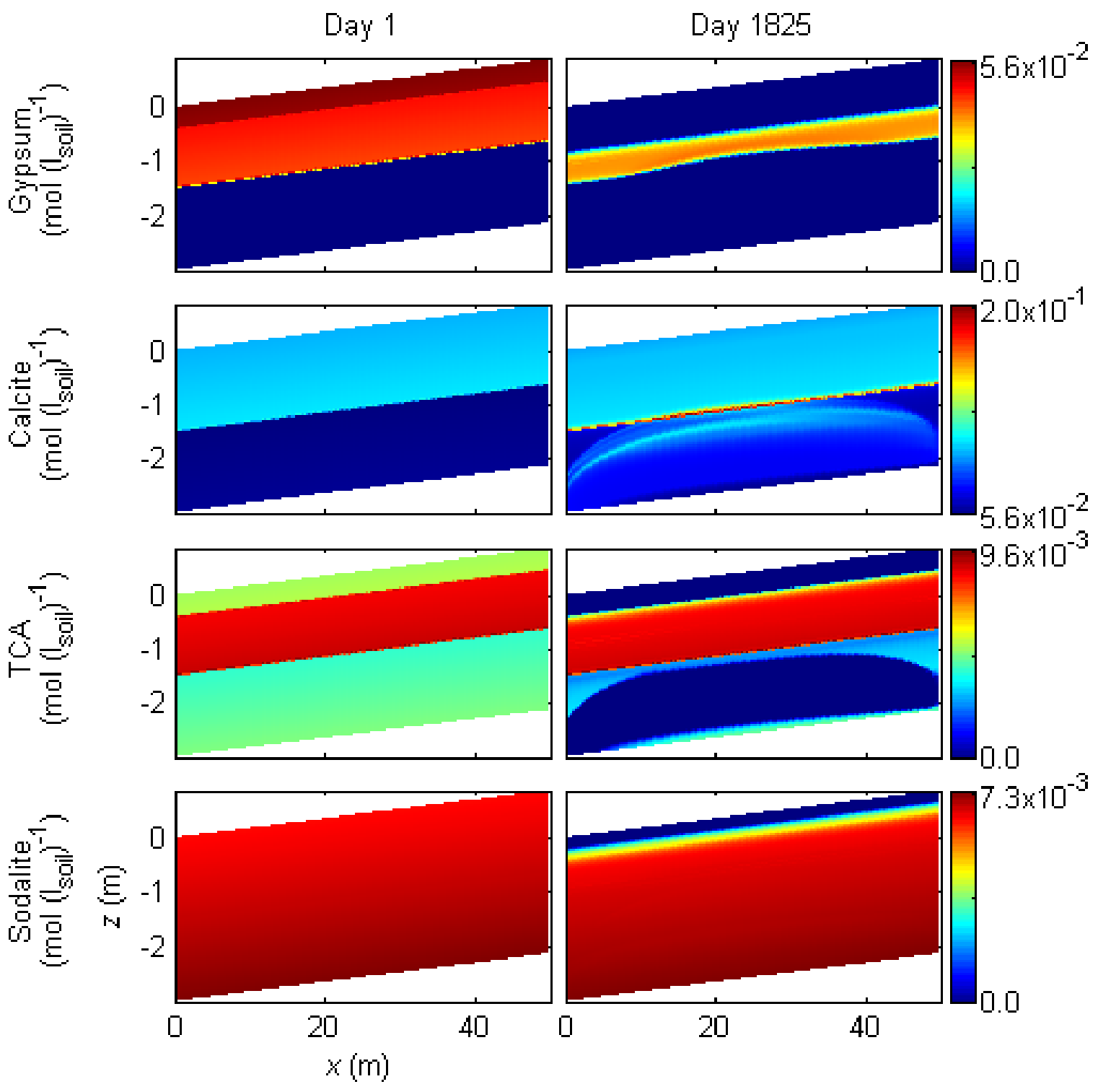

Fig. 16: Evolution of the main minerals of the surface cover simulation for 1 and $1825 \mathrm{~d}$. 


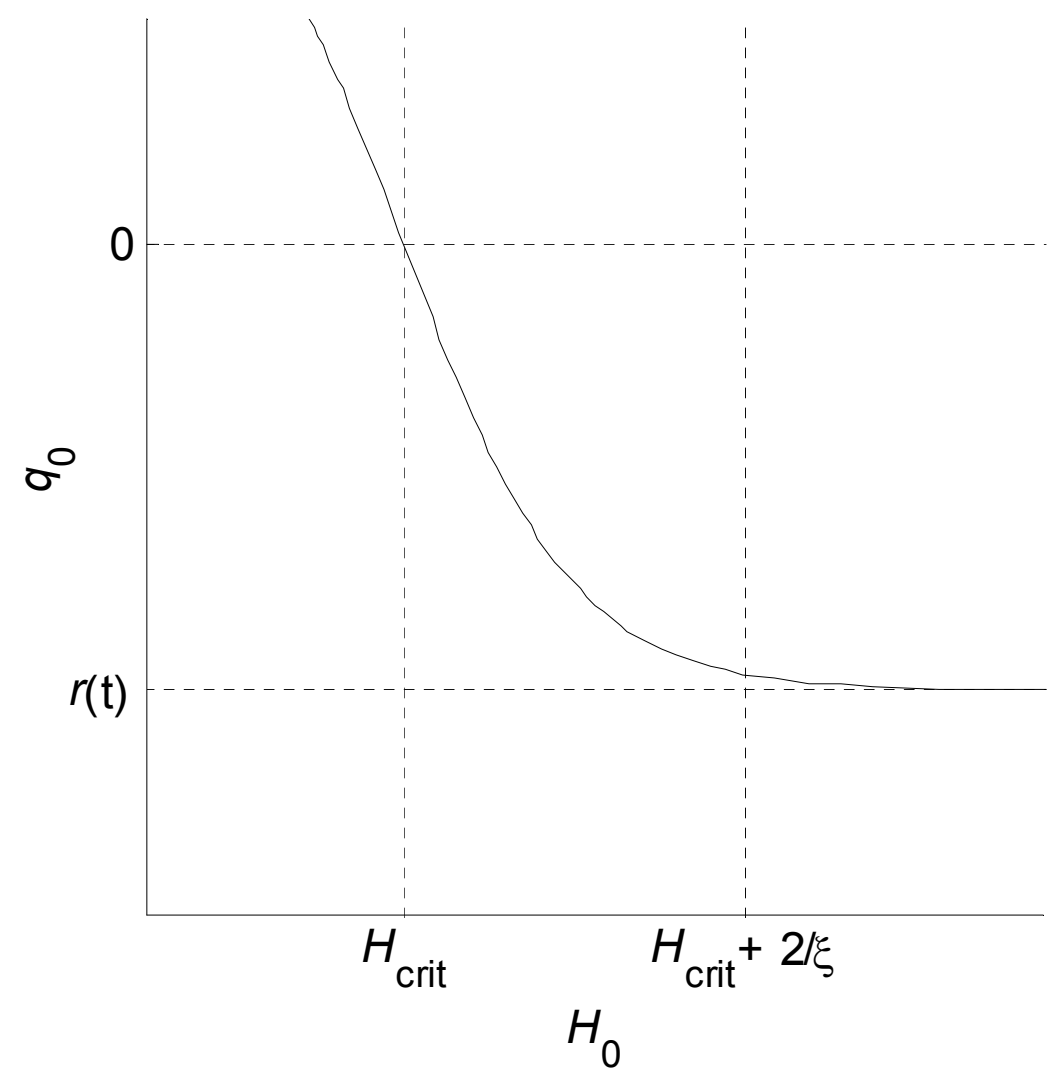

Fig. 17: Boundary flux during negative recharge in the vicinity of the critical pressure head $\boldsymbol{H}_{\boldsymbol{a}}$. 


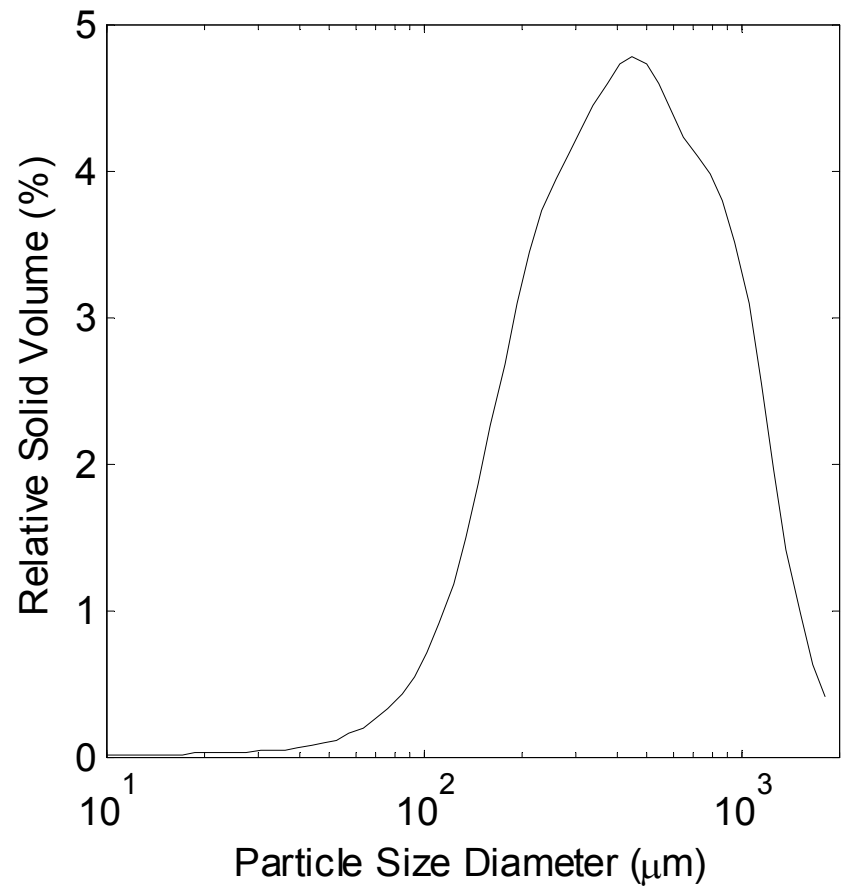

Fig. 18: Particle size distribution of washed residue sand. 